\title{
Black Women Speak: Examining Power, Privilege, and Identity in CS Education
}

\author{
YOLANDA A. RANKIN, Florida State University, USA \\ JAKITA O. THOMAS, Auburn University, USA \\ SHEENA ERETE, DePaul University, USA
}

Despite the increasing number of women receiving bachelor's degrees in computing (i.e., Computer Science, Computer Engineering, Information Technology, etc.), a closer look reveals that the percentage of Black women in computing has significantly dropped in recent years, highlighting the underrepresentation of Black women and its negative impact on broadening participation in the field of computing. The literature reveals that several K-16 interventions have been designed to increase the representation of Black women and girls in computing. Despite these best efforts, the needle seems to have barely moved in increasing the representation or the retention of Black women in computing. Instead, the primary goals have been to recruit and retain women in the CS pipeline using gender-focused efforts intended to increase the number of women who also identify as members of racialized groups. However, these gender-focused efforts have fallen short of increasing the number of Black women in computing because they fail to acknowledge or appreciate how intersectionality (the overlapping social constructs of gender, race, ethnicity, class, etc.) has shaped the lived experiences of Black women navigating the computing pipeline. Without honest dialogue about how power operates in the field of computing, the push for racial equality and social justice in CS education remains an elusive goal. Leveraging intersectionality as a critical framework to address systemic oppression (i.e., racism, gender discrimination, power, and privilege), we interview 24 Black women in different phases of the computing pipeline about their experiences navigating the field of computing. An intersectional analysis of Black women's experiences reveals that CS education consists of saturated sites of violence in which interconnected systems of power converge to enact oppression. Findings reveal three primary saturated sites of violence within CS education: (1) traditional K-12 classrooms; (2) predominantly White institutions; and (3) internships as supplementary learning experiences. We conclude the article with implications for how the field of CS education can begin to address racial inequality that negatively impacts Black girls and women, thus contributing to a more equitable and socially just field of study that benefits all students.

CCS Concepts: - Social and professional topics $\rightarrow$ Computing education; Computer science education;

Additional Key Words and Phrases: Black feminism, black women, CS education, intersectionality, racism

\footnotetext{
This research is generously supported by the National Science Foundation Grant no. 1937759.

Authors' addresses: Y. A. Rankin, Florida State University, 142 Collegiate Loop, Tallahassee, Florida, USA, 32306; email: yrankin@cci.fsu.edu; J. O. Thomas, Auburn University, 3101G Shelby Center, Auburn, Alabama, USA, 36849; email: jnt0020@auburn.edu; S. Erete, DePaul University, 243 South Wabash Avenue, Chicago, Illinois, USA, 60604; email: serete@cdm.depaul.edu.

Permission to make digital or hard copies of part or all of this work for personal or classroom use is granted without fee provided that copies are not made or distributed for profit or commercial advantage and that copies bear this notice and the full citation on the first page. Copyrights for third-party components of this work must be honored. For all other uses, contact the owner/author(s).

(c) 2021 Copyright held by the owner/author(s).

1946-6226/2021/10-ART26 \$15.00

https://doi.org/10.1145/3451344
}

ACM Transactions on Computing Education, Vol. 21, No. 4, Article 26. Publication date: October 2021 
ACM Reference format:

Yolanda A. Rankin, Jakita O. Thomas, and Sheena Erete. 2021. Black Women Speak: Examining Power, Privilege, and Identity in CS Education. ACM Trans. Comput. Educ. 21, 4, Article 26 (October 2021), 31 pages. https://doi.org/10.1145/3451344

\section{INTRODUCTION}

As with most STEM disciplines, the field of computing has long positioned itself to be beyond the reach of politics and social issues that reflect subjective viewpoints rather than objective theories, characterizing itself as a discipline that values meritocracy. However, recent events, including the horrific murders of Breonna Taylor [39, 76] in March 2020 and George Floyd in May 2020 [72], both at the hands of police, have called attention to how discrimination on the basis of race and gender has contributed to racial inequalities in the United States and beyond. Black scholars in the field of computing further testify to inequities that create a hostile environment for Black students and faculty who aspire to careers in computing [7, 29, 44, 106]. One of the most disconcerting issues that has emerged is the naivete of White colleagues in the field of computing who state that they were ignorant of how Black people in the United States are subjugated to differential treatment and racism on a daily basis, especially when these same colleagues have conducted and been recognized for CS education research that supposedly pushes for inclusion and equity for Black students and other marginalized populations [41].

As Black scholars, we question why the field of computing, specifically CS education, has denied the existence of racism for so long. Collins [17] refers to this kind of feigned ignorance as a camouflage for epistemic power in which those who are empowered and privileged within an interpretive community (i.e., the field of computing) dictate the rules for what is considered acceptable knowledge. This notion of acceptable knowledge reflects and protects the dominant group's status of power and privilege, otherwise known as epistemic oppression, while rejecting and silencing other forms of knowledge produced by marginalized populations, which is referred to as epistemic violence [17]. Epistemic oppression has enabled CS education to endorse a false narrative of being a colorblind and meritocratic discipline, a racist ideology that refuses to acknowledge race as a contributing factor to the differential treatment that racialized groups experience [9]. Rather than including historically excluded groups as a mechanism for engendering diversity, colorblind ideology maintains whiteness as the established norm, rendering people of color as invisible and an aberration in the field of computing $[9,86]$.

Given the low percentages of Black Americans in the field of computing [112], numerous interventions and strategies in CS education have been employed to intentionally increase the representation of Black students. For example, the STARS Alliance has established partnerships with Historically Black Colleges and Universities (HBCUs) to provide research and mentorship opportunities to encourage Black students to persist in the field of computing [23]. Leveraging the appeal of video games, Sheridan et al. [94] transition Black youth who initially represent novice game designers into eventually becoming experienced game designers and youth instructors in an afterschool program that empowers Black students to be creators of gaming technology. In a similar manner, Thomas et al. [102, 103] conduct a longitudinal study of Black middle and high school girls as they develop and apply computational algorithmic thinking skills in the context of designing video games that address social issues across multiple platforms. In the context of traditional classroom environments, Rankin et al. [84] leverage students' knowledge or everyday experiences with food to increase the retention of Black women in an introductory CS course. In another example, Digital Youth Divas provides a blended learning environment (online and offline) for Black and Brown middle school girls to create digital artifacts (e-bracelets) while developing 
their computational thinking skills and increasing their interest in STEM and sense of agency [79]. Despite these combined efforts, Black students, in particular Black women, remain underrepresented in the field of computing. This raises the question as to why the pendulum has not begun to swing the other way as it relates to the increased retention of Black women in computing.

In an effort to gauge women's interest in computing, a recent study [31] shows that Black women have the highest intent and desire to major in computer science (CS) compared to other racial groups of women. Despite their career aspirations, the 2019 Taulbee Survey reveals that, for Black women, the percentage of BS degrees awarded in CS is 4\% [112], and it has consistently remained between 3\% and 5\% since the Taulbee Survey first began disaggregating data in 2012 [111]. Such issues point to other significant factors that contribute to the low representation of Black women in the field of computing.

Recent studies conducted by Black scholars, a historically excluded population within the field of computing, point to examples of oppression and trauma that Black women have endured in order to persist in the field of computing [80, 81, 92, 95, 102]. Findings from this research testify to the hostile culture of CS education and reveal that systemic oppression (i.e., gendered racism, an act of violence) does indeed exist in the field of computing. Collins [17] suggests that scholars treat such violence as saturated sites of power relations. These "saturated sites bundle together practices, social institutions, representations, and patterns of everyday social interaction that appear and reappear across seemingly separate systems of oppression" [17, p. 238]. Saturated sites represent both hypervisible and ubiquitous intersecting power relations as seamless transactions in which those who are empowered and privileged oppress marginalized populations, inflicting violence on Black women of a physical, emotional, mental, spiritual, and even a professional nature (e.g., damage to one's academic career). It is a form of violence that does not necessarily leave wounds visible to the naked eye but harms and injures Black women and their humanity, nonetheless.

We argue that further research that examines systemic oppression in CS is necessary for three reasons. First, we need to hold the field of computing accountable for its role in enabling oppression that has resulted in the exclusion of Black Americans, particularly Black women. To hold the field accountable, we must expose how interlocking systems of power enable oppression in the field so that we know what it looks like and can assess its impact. Second, Black women in computing need more allies. As Black women, our lived intersectional experiences serve as evidence and testimonial authority of how power and privilege operate in the field of computing [17, 82]. In order to have more allies, we need more people to empathize with the collective standpoint of Black women in computing $[43,102]$. Finally, if we are truly committed to transforming CS education into an inclusive, diverse, and equitable community for all [77, 90], then we must take concrete steps to dismantle systemic oppression and its many manifestations in the field of computing. As an act of resistance as well as a resistant knowledge project, we take this opportunity to call out how power functions within computing to perpetuate systemic discrimination and gendered racism that negatively impacts Black women and other marginalized populations in the field of computing. We begin this examination by identifying saturated sites of epistemic violence within CS education as described from the first-hand accounts of Black women in the field as they navigate spaces in secondary and post-secondary CS education. As such, we pose the following research question: What are the saturated sites of epistemic power in computing education for Black women?

We begin this exploration with Black women in computing for three reasons. First, Black women represent one of the most marginalized groups within computing and CS education [112]. Despite numerous interventions that have targeted Black girls [79, 87, 101, 103] in K-12 CS education, the needle has barely moved regarding the representation of Black women in the field of computing $[23,84]$. Furthermore, recent research reveals that Black women are managing to persist in the field 
of computing even though they experience hostility and discouragement and have virtually been erased from CS history [80, 82, 85, 102]. Second, as a resistant knowledge project, we aim to disrupt the homogeneous treatment of "women of color" who are often lumped into one group to preserve statistical significance, when that categorization represents incredibly heterogeneous populations of Black, Latina, Native American, Asian, Pacific Islander, and other marginalized women who each deserve to be centered and examined in their own right $[47,75]$. This becomes relevant in that our study demonstrates issues that are specific to Black women's experiences in computing. We have yet to determine if other heterogeneous populations of women of color are experiencing similar issues or if there are indeed unique differences among women of color based on race, class, sexual orientation, nationality, and so on $[48,49]$. As such, this work represents an important step toward acknowledging the heterogeneity of women of color by specifically examining the lived experiences of Black women as one segment of this population. Finally, in service to intersectional computing [55, 82, 102], we hope that this work and its methods will be taken up by members of other historically excluded groups within computing and leveraged to replicate these types of studies within communities so that we can begin to understand the commonalities and differences among marginalized groups across many axes (e.g., race, gender, sexual orientation, ability, nationality).

\section{BACKGROUND}

Little CS education research has specifically examined Black women's experiences navigating the computing ecosystem $[80,82,95,102]$. Therefore, we seize the opportunity to center the experiences of Black women in the field of computing, applying Black feminist epistemologies $[5,6,62]$, Black feminist thought [16], and intersectionality [17, 18, 21, 22] as critical frameworks for understanding systemic oppression that Black women experience, particularly the saturated sites of power and epistemic violence within computing education. We conclude this section with an overview of power and privilege within CS education.

\subsection{Overview of Intersectionality}

An intersectional approach in education becomes necessary when seeking to understand underrepresented or marginalized populations who are often relegated to the outer fringes of society because of the historical and political ramifications of White supremacy, racism, gender and sexual discrimination, classism, and other forms of oppression prevalent in the United States $[17,18,20,21,65,77]$. Collins and Bilge [18] define intersectionality as "a way of understanding and analyzing the complexity in the world, in people, and in human experiences...conditions of social and political life and the self can seldom be understood as shaped by one factor. They are generally shaped by many factors in diverse and mutually influencing ways" [18, p. 2]. Intersectionality takes a multidimensional approach to understanding how social constructs such as race, gender, class, physical ability (ableism), sexual orientation, and so on, contribute to one's sense of self (Who am I?), one's day-to-day reality (How do I see the world?), and how others relate to self (How do others see me?).

Intersectionality is not a new concept since scholars in the social sciences and humanities have embraced intersectionality as an analytical framework for studying indigenous populations in North America, Europe, and the Global South (countries located in Asia, Africa, Latin America, and the Caribbean). Long before the term intersectionality was introduced, the origins of intersectionality date back to the early 19th century when coalitions of Black women, Chicanas, Native American women, Afro-Brazilian women, and other women of color fought against oppressive forces that denied their humanity and civil rights [16, 18, 20]. Deconstructing the power structures of racism and gender discrimination, Crenshaw [20-22] leverages intersectionality to critique the 
American legal system for its inept ability to render due process for Black women in the United States who have suffered discrimination and violence because of their overlapping racial and gender identities and socioeconomic status. Collins and Bilge [18] refer to this as critical praxis-the practice of identifying and deconstructing power structures of oppression that affect marginalized populations. Because of the acute underrepresentation of Black women, Latinas, Native American women, and so on, in the field of Computing, intersectionality has emerged as a critical framework for acquiring a deeper understanding of the lived experiences of women of color as they navigate the computing ecosystem and how these experiences influence their ability to persist in Computing $[36,48,49,75,112]$. As such, more work needs to be done that centers particular marginalized groups.

We start here with Black women in an effort to nuance the category of "women of color" by examining and beginning to understand the structure of power grids in computing experienced by the heterogeneous women who make up that category (e.g., Black women, Latina women, Native American women, Pacific Islander women). Likewise, we as Black women in computing apply intersectionality as a critical framework to identify systemic oppression that lies embedded within the very discipline of computing. One of the guiding premises of intersectionality is its ability to expose the inner workings of power relations that create social inequalities for historically excluded populations [17]. Collins describes these power relations as indicative of a dominating matrix of power that exemplifies racism, sexism, socioeconomic status, homophobia, ableism, xenophobia, and so on. Collins also notes that "Intersectionality's emphasis on intersecting systems of power suggests that distinctive forms of oppression will each have its own power grid, a distinctive 'matrix' of intersecting power dynamics" [17, p. 239]. Intersectional analysis of power becomes necessary for identifying overlapping systems of power that mutually influence one another.

\subsection{Black Feminist Thought}

For hundreds of years, Black women in the United States experienced racism and gender discrimination because of their skin color and sex. Black women shared an awareness of how their sexual identity combined with their racial identity created a unique situation, "one that led to the need to develop a politics that was antiracist, unlike those of white women, and antisexist, unlike those of Black and white men" [15]. Black women such as Sojourner Truth, Harriet Tubman, Ida B. Wells, Mary Church Terrell, Barbara Smith, Beverly Smith, Audrey Lorde, bell hooks, Nikki Giovanni, Barbara Ramsey, and many others established Black feminism as a critical lens for understanding the intersectional experiences of Black women in the United States. Thus, intersectionality gave birth to the Black feminist movement, the political struggle for Black women's humanity, and the fight for social justice that gained momentum in the 1970s. Because of their intersectional identity, Black women have developed a unique standpoint. Black women's collective standpoint is borne of standpoint theory-knowledge that stems from one's social position within a society and rejects a perspective that regards the world as made up of observable and measurable facts [43]. For example, standpoint theory posits that to understand inequality one must begin with marginalized people who have "expert" knowledge or lived experiences dealing with interlocking systems of oppression [16]. Likewise, standpoint theory contends that experiential knowledge is to legitimize "data" for analyses and should be used in order to advance feminist ways of thinking.

First introduced as a critical social theory by Patricia Hill Collins, Black feminist thought positions Black women as knowledge agents or experts (not objects of study) about what it means to be a resilient Black woman [16]. Black women face systemic oppression on a daily basis while fighting for their rights as human beings and advocating for the humanity of others. Black feminist thought draws attention to the historical legacy of Black women in the United States, chronicling their journey from slavery through the Jim Crow South to the Civil Rights Movement and the 
current state of affairs in the 21st century $[15,16]$. While enduring subpar living conditions for several generations, Black women have established a unique and collective standpoint comprised of the shared historical ramifications of slavery which created the current political, economic, and social standing of Black women in the United States [16, 43]. Positioned as intellectuals, the lived experiences of Black women testify to the homogeneity of shared race, gender, and sociocultural norms while simultaneously accommodating the heterogeneity of Black women's lived experiences that ensue from differences in socioeconomic status, sexual orientation, physical abilities, and other attributes. The culmination of diverse perspectives grounded in intersectional similarity define the notion of Black women's collective standpoint [16].

Leveraging an intersectional vantage point, Black feminist thought first introduced the matrix of domination through the unique perspective, expertise, and intimate knowledge of Black women who had been subjugated to inhumane conditions and consequently, an inconsequential existence in mainstream American society [16]. In her groundbreaking work Black Feminist Thought: Knowledge, Consciousness, and the Politics of Empowerment, Collins described the matrix of domination through which structural oppression manifests:

\begin{abstract}
"Whether viewed through the lens of a single system of power, or through that of intersecting oppression, any particular matrix of domination is organized via four interrelated domains of power, namely, the structural, disciplinary, hegemonic [now called cultural] and interpersonal domains. Each serves a particular purpose. The structural domain organizes oppression, whereas the disciplinary domain manages it. The [cultural] domain justifies oppression while the interpersonal domain influences everyday lived experience and the individual consciousness that ensues." [16, p. 276]
\end{abstract}

These different domains of power reflect the complexity of power relations that mutually reinforce one another to inflict various forms of violence be it physical, psychological, professional, or even spiritual on Black women and other historically excluded groups in computing. For example, in prior research, Black women in computing refer to personal interactions with college professors and fellow classmates who question their intelligence and competency, an example of the interpersonal domain of power, and inflict psychological trauma that diminishes Black women's confidence in themselves and in their ability to succeed in the field of Computing [82]. While Black feminist thought centers Black women's experiences, expertise, and knowledge, it also views Black women's fight against social inequality as part of a global struggle for human dignity and social justice for all people. Thus, Black feminist thought is a clarion call to build coalitions with others to dismantle the matrix of domination and systems of oppression that inflict violence, ultimately transforming the organizations and spaces in which we as human beings move and interact.

Because we identify as Black women scholars and activists, we apply Black feminist thought as a critical framework to expose the systemic oppression that Black women in the field of computing have endured. This approach affirms Black women as agents of knowledge and justifies using their exact words or testimonial authority to capture their diverse perspectives navigating the computing ecosystem [17]. Black women sharing testimonies of their lived experiences and speaking their truth is an act of epistemic resistance in defiance to epistemic violence-the disbelief, denial, and/or dismissiveness of a historically excluded group's lived experiences [17]. Epistemic violence is accomplished through testimonial quieting and testimonial smothering, two specific forms of epistemic silencing that Black people (and other historically excluded populations) face in an effort to "suppress the ideas of subordinated people" [17, p. 133]. These efforts are deeply embedded in academic settings where testimonial quieting and testimonial smothering work together to silence subordinated people. For example, testimonial quieting occurs when the more dominant social group ignores what the historically excluded group has to say, thereby denying 
subordinated people the space to be heard [17]. In academia, testimonial quieting emerges when scholars use the supposedly objective peer review process to dismiss Black participants' narratives as unsubstantiated evidence or advise Black scholars to water down their ideas. In contrast, testimonial quieting takes place when members of the historically excluded group realize that their lived experiences are deemed as illegitimate knowledge and therefore, engage in self censorship by refusing to speak about or express their lived experiences. Incidents of testimonial smothering emerge when Black scholars feel that they must be silent rather than testify to the partial treatment they receive from their White colleagues in order to be successful in the academy [26]. "Self censorship is often the cost of being heard at all [..] people who are repeatedly ignored [or whose ideas or perspectives that run counter to the dominant narrative] quickly learn from the protections of seeming acquiescence" [17, p. 134]. This summarizes the risk of speaking up, being heard, and then being penalized for speaking one's truth versus just saying nothing and suffering in silence. Either option is indicative of epistemic violence.

\subsection{Intersectional Computing}

Since the late 1990s, a burgeoning body of CS education research that emphasizes the recruitment and retention of women in computing has emerged [8, 14, 33, 35, 40, 67], drawing attention to how the "one size fits all" pedagogical approach caters more to men/boys while alienating women/girls. Though CS education has managed to pivot in an attempt to better cater to women $[4,33,34,88,100]$, less research has addressed the issue of systemic gendered racism that women of color, in particular Black women, face in computing [82, 99, 102]. Given Black women's unique vantage point of being both Black and women [16, 95], adequate analytical tools become necessary for examining the intersection of race and gender as interconnected systems of power that oppress women of color [17]. As such, the computing field has begun to engage with intersectionality-a critical social theory for examining the complexity of how "systems of power co-produce one another in ways that reproduce both unequal material outcomes and the distinctive social experiences that characterize people's experiences within social hierarchies" [17, p.46]. For example, Thomas et al. [102] document the experiences of 11 Black women in computing, introducing the concept of intersectional computing while identifying multiple coping strategies that enable them to successfully navigate the computing ecosystem. In a similar manner, Rankin and Thomas interview 14 Black women in different stages of the computing pipeline (e.g., graduate student, industry professional, tenure-track faculty), acknowledging that HBCUs provide a more supportive environment compared to predominantly White institutions, which contributes to Black women's persistence in computing. From an industry perspective, Yamaguchi and Burge [107] outline concrete steps for ensuring Black women's career progression, including tying the company's bottom line to sufficient leadership development opportunities for Black women employees.

Despite the uptake of intersectionality in the field of computing, we raise serious concerns about how our colleagues are misappropriating intersectionality, ignoring key aspects of what makes intersectionality a critical form of inquiry and praxis in the fight for social justice in the context of CS education. "People generally use intersectionality as an analytic tool to solve problems that they face or others around them face" [18, p. 2]. However, a number of CS education scholars casually use the term intersectionality to justify their research of minoritized communities, applying a deficit-model approach to "other" or position these same communities as being exotically different while blaming them for their perceived shortcomings [36, 81]. Scholars who tend to do work within minoritized communities in an effort to broaden participation in computing often fail to acknowledge their power or privilege, nor do they draw attention to the various forms of systemic oppression or their historical impact that created the racial and gender inequities that exist within CS education today $[81,85,92]$. Despite having good intentions, our colleagues become complicit 
in the endless cycle of violence that historically excluded populations continue to endure. Intersectionality, when applied as a critical praxis, requires scholars to reveal the interconnected systems of power at work and how they operate to create social inequities that exist in CS education [17, 18, 85]. Intra- and inter-analyses of power become essential for creating more equitable learning environments that increase the recruitment and retention of Black women in the field of computing.

Collins [17] suggests that describing or identifying violence as a saturated site of power relations does four important things. First, it makes the workings of power within and across oppressive systems visible, providing "an entry point into theorizing intersecting systems of power" [17, p. 238]. Second, it allows us to examine the "conceptual glue" that binds intersecting systems of power together (ibid.). This is important, because oppression is frequently used to justify dominant narratives that seek to explain why things are the way they are. Third, it opens up "new pathways for conceptualizing domination" used to subjugate, assimilate, and surveil. Finally, it "sheds light on resistant knowledge projects of anti-violence initiatives" (ibid.). This might include strategies that Black women develop to cope, navigate, and fight even as they experience saturated sites of power relations and epistemic violence in computing and CS education.

We demonstrate one example of how to identify a saturated site of violence in CS education. A dominant narrative that is prevalent in CS education at the undergraduate level is that students are most likely to succeed in CS as a major if they have had prior programming experience as well as computing exposure, family and friends in the field, and have been exposed to Calculus in high school [89]. Those students whose backgrounds are not reflective of this narrative often struggle in undergraduate CS courses because they are perceived as incapable of succeeding or lacking "grit" [27]. Rather than perceiving these students as using alternate paths to enter the field of computing, they are perceived as less "fit" or not "CS material" [102]. Subsequently, proper support for alternate pathways into the field of computing do not exist, as the assumption is that everyone conforms or assimilates to the dominant narrative. As we will see in this article, Black women often run squarely into these dominant narratives and have to figure out ways to combat, resist, and overcome the hostile environments that exist because of these dominant narratives, rife with assumptions that often render Black women to the margins of Computing. Intersectional computing aims to provide CS education with the necessary vocabulary and tools (including theories and methods that have yet to be developed) for examining how power plays out in the field of computing so that it can be identified, understood, and, ultimately, dismantled.

\subsection{Power and Injustice in CS Education}

Very little CS education research that seeks to increase diversity, inclusion, and equity discusses or even mentions the ramifications of power and privilege and how these ramifications produce the social inequalities evident in the field of computing $[89,105]$. Such overt omission of the acknowledgement of power and privilege in the field of computing enables intersecting oppressions to continue to thrive on multiple levels. For example, that lack of acknowledgement of power in computing conveys the message that computing is a colorblind meritocracy, a level playing field in which anyone can succeed if she works hard enough, an example of the cultural domain of power [18]. However, Black women tell a different story about their computing education experience, one in which they face rejection from their non-Black classmates when seeking partners for group assignments [71] or differential treatment (ignored) compared to White women graduate students who receive mentorship for understanding the rules around how to navigate graduate school [82]. Adding to the complexity of this example is disciplinary power.

Without an in-depth, honest conversation about power relations within the field of computing, one cannot expect to engender social change that equates to equity, justice, and liberation in the field of computing. For example, the primary focus has been numerous studies of interventions 
that target underrepresented populations such as women, African Americans, LatinX, Native Americans, Asian Pacific Islanders, and persons with disabilities [2, 23, 56, 57, 104, 105]. However, these same populations remain marginalized despite efforts to change the status quo [31, 112]. This raises the question: why have these interventions proven to be unsuccessful in significantly increasing the representation of marginalized populations in CS? The answer to this question lies in the careful examination of power relations in the field of computing.

As Black women in the field of computing, we call upon our intersectional experiences as legitimate "ways of knowing" how intersecting oppression in CS education functions as saturated sites of epistemic violence [16, 82]. Because of our lived experiences as Black women in computing, we conduct an intersectional analysis of power to explore Black women's experiences navigating the computing ecosystem and identify CS education as a saturated site of violence. This represents a critical yet necessary departure from previous discussions about diversity, inclusion, and equity in $\mathrm{CS}$ education. We argue that gendered racism, discrimination, sexism, abuse of power, dehumanization, and so on, represent various forms of violence that take place in CS education on a daily basis.

\section{POSITIONALITY STATEMENT}

Applying standpoint theory [43] as the motivation for our research, we include a positionality statement indicative of the research team. The research team includes three Black feminists who have strong interests in the disruption of the dominant sociocultural norms attributed to the field computing. Together, we represent more than 30 years of experience in the academe, conducting research that promotes a more complex narrative of the ways Black women's bodies move through the world and specifically, the computing ecosystem. Moreover, we interchangeably use Black women to refer to all women of the African diaspora. Motivated by the need for more equitable, inclusive, and diverse formal and informal learning environments in CS education, our lived intersectional experiences provide a posteriori knowledge about marginalization in the field of computing. Finally, we bracket our various sets of assumptions by including all variations in Black women's interviews, not rejecting those experiences that may be divergent from our own.

\section{METHOD}

\subsection{Participants and Settings}

Using the snowball sampling method, we initially sent an email to four Black women who were in different stages in the computing pipeline (i.e., graduate students, early career professionals, and department faculty) to participate in semi-structured interviews. Upon completion of the interview, each of these four Black women then recommended another Black woman who was willing to share her testimony and provided her contact information (email address). We repeated this cycle until we ultimately recruited a total of 24 U.S. Black women in different phases of the computing pipeline -2 CS faculty members, 16 early career professionals (less than 5 years working experience), 5 graduate students, and 1 undergraduate student. Seventeen of the 24 Black women attained their Bachelor's or Master's degrees in computing disciplines from HBCUs.

\subsection{Data Collection and Analysis}

After attaining Institutional Review Board consent for each participant, one researcher conducted the semi-structured interview, asking a series of questions, including but not limited to the following:

(1) Do you consider yourself to be a Black woman in computing? Why or why not?

(2) What is your current status in the field of computing?

(3) What motivated you to pursue a career in computing? 
(4) Describe your experiences as an undergraduate student.

(5) Did you enroll in a graduate school program? If yes, please describe your experiences as a graduate student.

(6) What challenges did you face being a Black woman in the field of computing?

(7) Which factors do you attribute to your ability to persist in the field of computing?

The names of all participants and corresponding identifying information (i.e., institutional affiliation) were replaced with pseudonyms to protect their identities. All 24 interviews were recorded and transcribed for data analysis purposes. We then conducted a content analysis of the interview transcripts. First, we read through each interview, identifying potential sites of violence based upon stages in CS education (e.g., K-12 education, post-secondary, undergraduate education, and graduate education), type of learning environment (e.g., classrooms, out-of-school programs, boot camps, informal study sessions, research labs, and internships), and type of institution (Historically Black College/University, Predominantly White Institution, government research lab and industry). Next, using in vivo coding (i.e., using the actual words of participants), we coded all 24 transcripts to identify, in their own words, multiple examples in which Black women were oppressed.

We then engage in an intersectional analysis of power for each of the identified scenarios. To do this, we apply Collins' $[17,18]$ approach for describing or identifying violence as a saturated site of power in CS educational settings, which was discussed previously though briefly. First, we explicitly name the intersecting systems of power described in each testimony (e.g., sexism, racism, classism, and so on) as well as who holds power. It is important to note that we must not think of these systems of oppression separately, but collectively as an integrated system of systems, which aligns with Black women testifying that it is virtually impossible for them to determine where one system begins and another one ends (e.g., to disentangle an aggression being rooted in racism or sexism). This is why intersectionality is such an important analytical tool: because it acknowledges the complexity of these interconnected systems and does not attempt to disentangle different types of oppression that are experienced simultaneously. Instead, it sheds light on how that particular configuration of intersecting systems of oppression impacts the lived experiences of Black women in Computing in a particular context.

Then we describe the "conceptual glue" that binds these intersecting systems together and the assumption(s) that those who hold power are employing and enacting to guide their interactions with Black women in these scenarios. Next, we examine the ways in which Black women are subjugated, surveilled, and/or expected to assimilate to "normative" ways of being and behaving in each scenario and its accompanying CS education space. We do this to identify "new pathways for conceptualizing domination," specifically making salient how intersecting systems of oppression dominate and the varied ways that domination manifests violently for Black women. Finally, we identify, if provided, ways in which Black women resist the violence they encounter, including strategies that Black women develop to cope, navigate, and fight these saturated sites of violence in different CS education contexts.

Here, we identify the three most prevalent saturated sites of epistemic violence in the field of computing that emerged from the data: (1) traditional K-12 classroom environments; (2) predominantly White institutions; and (3) internships, which we view as supplementary learning experiences to post-secondary CS education.

\section{FINDINGS}

We leverage the testimonial authority of Black women whose career trajectories-undergraduate students, doctoral students, early career industry professionals, and tenure-track CS facultyrepresent different phases of the computing pipeline [17]. Having managed to persist in the field of 
computing thus far, we share excerpts of their testimonies and conduct an intersectional analysis of power to depict how three primary saturated sites of violence emerge in CS education [18].

\subsection{K-12 Traditional Classroom Settings}

A Google report [52] released in 2016 revealed that $80 \%$ of K-12 students in the United States were exposed to CS in the traditional classroom setting, with more than half of White (58\%) and Hispanic (59\%) students granted access to CS curriculum as part of their K-12 education. In comparison, only $47 \%$ of Black students in the U.S. attended K-12 schools that offered required or elective CS courses, creating a seemingly unlevel playing field for Black students to excel in computing if relying on the dominant narrative of who is traditionally successful in CS $[13,52,66]$. We recognized a similar phenomenon for most Black women in our study since few of them had an opportunity to take a CS class in high school, instead enrolling in their first CS course in college [84].

5.1.1 Shannon's Testimony. In our study, for those Black women who did have the opportunity to enroll in CS courses during their K-12 experience, they often found that the course description did not align with the college-level introductory CS courses that they took. Shannon, an early career professional, shared her experience taking her first "CS class" in high school.

So we had - in my high school, we had one, I guess you could say, computer class, but it was more so focused on business, but we called it the "business computer class," but we didn't do anything technical in it. It was more so about how do you do financing or stuff. Like, we played a simulation game where you got money and you walked the person through a simulation. You had to build more wealth, basically. It had-except for the fact that you played the game on the computer-it had nothing to do with computers. (laughs)

Shannon described a high school "business computer class" that had little to do with students learning core CS principles such as the distinction between software and hardware, algorithms, or programming. Though the class leveraged the appeal of video games to teach students about wealth management, students did not learn how to design or develop video games. It was not clear if the teacher was even aware that the class did not satisfy the Computer Science Teacher Association K-12 standards for high school CS course curriculum [3]. Drawing on our experiences as instructors of summer computing camps that target middle and high school students and entrylevel CS courses in college, we recognized that playing a video game about wealth management did not equate to an introductory CS course. A significant antecedent, Shannon graduated from a rural high school that served a predominantly Black student population, a school with limited resources such as teachers who were adequately prepared to teach high school CS classes [38, 59]. In our study, several Black women who also grew up in rural areas with a significant Black population, reported a similar experience of the lack of exposure to CS education during their high school years, a clear indication that Black students in rural areas were often at a disadvantage due to geographical locations and their associated economic challenges [1, 13, 66].

The inner workings of power are made visible through how systemic racism and classism work together in the K-12 education system to create unequal outcomes for Black students in rural areas. The post-Reconstruction era and racist Jim Crow policies make it virtually impossible for Black Americans, especially those living in rural areas, to achieve upward mobility in society [1, 11]. To this day, southern congressman and national politicians in opposition to the Civil Rights movement in the 1960s and more recent protests against anti-Black racism, promote racist policies that continue to oppress Black Americans $[1,11,46]$. This so-called "southern strategy" has driven conservative politics and policy over the past 50 years, especially creating vastly different lived realities for Black Americans in urban and rural areas [42, 93]. "It is not random that the areas with 
the lowest economic mobility are those with high populations of African Americans. This history of both explicit and structural racism has led to policies that have maintained and exacerbated racial disparities in many outcomes" [1].

One of the long-term effects of structural racism in K-12 education is the continued racial disparity that contributes to the academic achievement gap that exists between Black and White children in the U.S. $[13,66]$. This becomes evident in the common practice of White privilege or "upholding Whiteness" in K-12 education [96]. White privilege represents a system of opportunities and benefits given to people simply because they are White while denying the same opportunities and benefits to non-White populations [24, 70]. The common practice of White privilege manifests itself in the K-12 education system in various forms, including allocating limited resources (if any) to predominantly Black student populations, more severe punishment of Black girls [64], teachers' low expectations of Black students' academic achievements [37], and other anti-Black racist policies [24]. For example, the lack of CS courses available at Shannon's high school located in a rural area with a predominantly Black student population and the misrepresentation of course content as being CS, even when the course has no relationship whatsoever to CS.

Borrowing Schneider and Gersting's [91] definition, CS is the study of algorithms that leverage the capabilities of the computer as a tool for problem solving. CS is not typing on the keyboard, creating a webpage, or taking a class that emphasizes digital literacy (e.g., becoming proficient using Microsoft Office products). Labeling any high school class that uses computers to deliver content as being indicative of CS education results in a conceptual mismatch for students, especially when these same students enroll in their first college-level CS course only to realize that the "business computer class" in high school was not a CS course. Often in high schools that serve large Black student populations, especially in poor areas, digital literacy classes are labeled as "computer science classes" despite available alternatives for high school CS curriculum (e.g., Exploring Computer Science) [68]. This common practice, with origins well before the Brown v. Board of Education decision in 1954 [74], represents a long tradition of poorly trained teachers, subpar course offerings, and inadequate resources when it comes to the education of Black children in the United States $[58,59]$. This is the conceptual glue that binds together the intersecting systems of racism, classism, and nationalism as to which racialized groups have civil rights in the U.S., a continuous battle as evidenced by current protests and uprisings that call for social justice for Black people [19, 39]. This conceptual glue ensures that Black women like Shannon will enter their undergraduate CS departments differently than the dominant narrative of having prior computer programming experience in K-12 education [84]. Though some Black women's entry point into CS education begins at the undergraduate level, a different yet not an impossible path, structural racism deems them as being deficient and ill-equipped to succeed in the field of computing.

5.1.2 Aaliyah's Testimony. In contrast to the "business computer class," Aaliyah, a current graduate student, talked about her experience of learning how to program for the first time in an introductory CS course offered at her high school.

In high school, my instructor, she was just not a very nice person, so it wasn't very easy to learn from her. She wasn't very approachable so...she's the type of instructor where if you ask her a question she kind of replies as if you're incompetent, so you don't want to ask her a question because then she's going to make you feel stupid. And she wasn't nice. She was a very mean person, and she always kept the classroom cold. Like, she would always keep her windows open even when it was wintertime and it was snowing outside because she said she wanted to minimize infections in her classroom or something. It was something weird. It's like she wanted us to hate coming to her class. It's like, she desired that, and 
she had her favorites, which of course I wasn't one. Of course, with my experience, you can tell I wasn't one of them. But yeah.

One of two Black girls in the high school CS class, Aaliyah perceived her high school CS teacher, a White woman, to be non-approachable, intentionally inflicting physical abuse on her students by keeping the windows up in the classroom during the winter months "to minimize infections." Consequently, Aaliyah and other students were cold and physically uncomfortable, which created a less than favorable environment for learning. Aaliyah realized that she was not one of the teacher's favorite students (less is known about the teacher's attitude toward the other Black girl in the class.) As a young Black high school student being exposed to CS for the first time, Aaliyah's teacher used her authority via her social interactions with students (interpersonal domain of power) to create a hostile classroom environment. Unsurprisingly, Aaliyah's interest in learning CS was effectively stifled. It would be several years later before she enrolled in a college-level CS course and discovered that she liked programming, eventually deciding to pursue a graduate degree in computing.

Aaliyah's experiences testify to the nuances of how power operates inside a high school CS classroom. First, the White teacher wields power in the manner of how she chooses to respond to Aaliyah's questions, belittling her for asking questions. Second, she creates a hostile classroom environment that subjects students to cold temperatures and physical discomfort. The conceptual glue that binds together the intersecting oppressions of racism, classism, and ability (one's "fitness" to engage in computing) is the teacher's reaction to questions raised during class discussion. Instead of creating an environment where ideas, thoughts, and views are welcomed and examined, she engages in epistemic violence through quieting (i.e., teacher mockingly answers students' questions) and induced smothering (i.e., students censor themselves for fear of being judged as incompetent and "feeling stupid"). This type of subjugation in secondary CS classrooms can cause Black girls to assimilate [54] and "suffer in silence," exacerbating the isolation and sense of not belonging that Black women continue to experience as CS undergraduates, an example of the psychological and emotional trauma that often begins in K-12 education [82, 102].

5.1.3 Camille's Testimony. Some Black women in our studies appreciated the opportunity to be exposed to CS education at the high school level, even if others questioned Black girls' ability to meet academic expectations. Camille reflected on her experience taking an AP CS course in high school.

So I'll start with I went to a predominantly white high school, where I was one of three black students in any of my AP classes. I think I'm the only one that ever took all AP exams - or all AP classes. I ended up taking like 11 AP exams to prove a point, because despite being one of the better students in my cohort in high school, I was consistently being told that I - that AP classes would be too hard for me. Then this, again, influenced my choice to take all AP classes in my senior year, but then also to take all AP exams...I think me being a woman of color, what I do best is problem-solve. I was looking back at my high school experiences, when teachers were telling me I couldn't be, you know, an AP student despite getting great grades, despite getting the second highest test in whatever class, I was being told I couldn't be an AP student. I didn't look at that as like, "Oh, well, I guess I'm not meant to be an AP student." I think, "How can I solve - I used to think, how can I solve this problem? How can I go to the counsellor? How do I get a waiver to override what my teacher's saying about me? How do I fight for my spot to be in these spaces, these higher academic spaces?" And I think that's something that women of color, no matter where we're from, no matter what our experiences are, because of the way that 
the tech industry treats us and values us and the way that we're represented in this field, I think we all learn how to do that. We all learn how to fight for our place.

Camille talks about the lack of support she received when she expressed interest in taking AP courses at a predominantly White high school, including the AP CS course. Instead of letting the low expectations of her teachers persuade her to avoid AP courses, Camille views the situation as a problem to be solved, something that she is accustomed to doing. Refusing to take no for an answer, Camille petitions the high school counselor and receives permission to take the AP CS course along with other AP courses. Taking 11 AP exams just to prove a point, she exceeds her teachers' expectations and performs well academically in her AP courses. What was once perceived as an obstacle becomes a stepping stone to Camille's foray into the field of computing. Camille considers having to fight for her right to take an AP CS course, and subsequently, her place as a Black woman in society, as just another typical day of her existence. She indicates that this is par for the course for any Black woman who aspires to a career in the technology sector, another saturated site of violence. While there may be applause for Camille's determination and tenacity that ultimately resulted in her triumph, lauding the coping strategies that Black women utilize is problematic in itself as this does not address the oppressive systems that require coping mechanisms that enable Black women to survive-but not thrive-in computing. Hence, it becomes imperative that we do not normalize the hoops that Black women jump through just to have the same opportunities as their non-Black counterparts (e.g., to perform two to three times better to be recognized as merely competent) [105]. Instead, we must break down the systems that require coping and survival mechanisms.

This testimony demonstrates one way in which power is used to oppress Black high school girls and how one Black high school girl decides to exercise her epistemic resistance to overcome oppression. The teachers at this particular predominantly White high school perpetuate the dominant narrative that Black students are intellectually incapable of performing well in AP courses and therefore, should not be allowed to take any AP courses, regardless of their current academic standing. While we do not know the racial identity of these teachers, nonetheless, they uphold Whiteness as the standard for who is capable of doing well in AP courses, a racist ideology that implicates White students as being more intelligent and intellectually superior to Black students. The conceptual glue at work in this example is how systemic racism in the K-12 education system continues to oppress Black students despite their academic performance or interest in taking college-preparatory courses. This is not an accident as systemic racism seeks to uphold racial hierarchies that benefit White students (e.g., White students being exposed to college-preparatory courses to increase the probability of them doing well in college) while simultaneously invoking disadvantages for Black students and other students of color (e.g., Black students denied permission to take college-level courses in high school to maintain the student achievement gap between Black and White students).

Leveraging the power of self-definition [16], Camille refuses to be subjugated via the organizational structures of power [18] at work in K-12 education. As an act of resistance [16], Camille charts her own path into CS education, choosing to ignore the negative opinions of her high school teachers and seeking support and approval from her high school counselor, a significant strategy that goes beyond her teachers' circle of influence. Camille's determination to take any AP class she chooses provides her an opportunity to be exposed to CS prior to college and paves the way for her to navigate the field of computing, later attaining both undergraduate and graduate degrees in computing related fields. In essence, Camille opposes the racial hierarchy in K-12 CS education, and this makes all the difference in her future career trajectory, an opportunity denied so many Black girls in the United States. 
These three testimonies demonstrate how high school CS classrooms become saturated sites of violence for Black girls due to the lack of equitable and readily available resources and poorly trained White teachers who are insensitive to how Black girls live and move through the world. The lack of empathy for Black girls and women perpetuates dominant narratives and enforces White supremacy ideology that feeds into the deficit-model justification for the so-called Black student achievement gap $[25,59,66,78]$. Rather, we acknowledge the existence of racial inequality and social injustice in K-12 CS education and prevalent in K-12 education, more broadly, that negatively affect Black students, an outcome of systemic racism and discrimination at work in the U.S. educational system.

\subsection{Predominantly White Institutions}

According to consistently collected data from more than 100 colleges and universities in the U.S. for several years [108-112], Black women remain vastly underrepresented in CS departments at predominantly White institutions (PWIs). Some of our participants matriculated into both PWIs and HBCUs for their undergraduate education (e.g., a dual degree engineering program in which the first 3 years were at a HBCU and the last 2 years were at a PWI) and/or their graduate education. In contrast to the nurturing environments often attributed to HBCUs, every Black woman who attended a PWI repeatedly described hostile experiences at both the undergraduate and graduate levels, making it clear that Black women were not welcome in computing departments at PWIs.

5.2.1 Nicole's Testimony. Nicole, who currently works in the technology industry, described her experiences as an undergraduate student trying to navigate group dynamics at a reputable PWI:

So when it came down to like studying between the students it was more so like you didn't really see like - the Asian students wanted to study with people who were other Asians or the Indian students wanted to study with the students who are Indian. It was more so everybody sort of had their clique I guess you could say. And it wasn't as welcoming as, oh, come study with us. It was more so trying to figure out how they're studying and you just relied on the same things. And then also trying to find the right people to study with too who will let you study with them.

Nicole remembered how racialized groups of students (i.e., Asians) studied together, because there was a critical mass of different racial groups of students of color. However, there were too few Black students in the computing degree program to form their own study groups, thereby isolating Nicole. For Nicole and other students of color, the problem was not one of separation, which is often the faulty misconception of whiteness [54]. Rather, the system of oppression was racism, which worked to exclude non-white students from predominantly white study groups. Though this experience took place on the campus of a PWI, other racial or ethnic groups of students of color were able to organize and support one another, creating a safe space that affirmed students' racial, ethnic, and cultural solidarity and protected them from racism and White supremacy [54]. In the case of Nicole, she was not readily invited to join other racialized study groups, including those that consisted of students of color, a common phenomenon in many departments at PWIs [71].

In the context of PWIs, the underrepresentation of Black students insidiously implies that they are less capable of doing computing, a common misconception that enables racialized or ethnicitized groups of students to judge Black students as being academically incompetent and/or inferior. As a result, other racial or ethnic groups of students often do not perceive Black students as their equals, contributing to the sense of not belonging and feelings of isolation that many Black women in computing experience [71, 82, 83, 102]. Here, we see an example of anti-Black racism-the idea 
that there is something inherently wrong with Black people, and as a result, they are perceived as an inferior race [54]. Anti-Black racism is at play as evidenced not only by the lack of invitation for Nicole to join the study group but also by the lack of Black students in the program in the first place. The misconception of Black students' ability is likely one of the reasons Nicole experienced exclusion from study groups by those who may identify as being of Asian descent. This is significant in that Asian students are not underrepresented in the field of computing $[63,112]$ and are stereotypically perceived as the model minority [60], arguably enjoying a certain degree of privilege denied to Black students. This is not to say that Asian or Asian-American students do not experience racism since we know that the myth of the model minority is only one example of racist rhetoric that perpetuates harm against Asian communities [12]. Rather, Nicole's testimony testifies to the fallacy of colorblind pedagogical strategies that fail to acknowledge or even address racial or ethnic tensions between students of color, let alone the racial tension that exists between Black and white students.

Nicole's experience reflects the common experience of what happens when Black women attempt to make "friends" and gain entry into collaborative study groups but are rejected and told they are not welcome. In this scenario, the power is held by White, Asian, and other students of color who have the benefit of being large enough in numbers to create racially or ethnically homogeneous study groups to create a network of support. The interpersonal domain of power reveals itself in the rejection of Nicole as a study partner for no clearly articulated reason. Instead, Nicole is left to wonder why she was not invited to join any of the study groups. Is it because she is Black? Is it because she is a woman or is it for some other unknown reason? Black women report spending a great deal of time trying to figure out if such behavior is because of race or gender, and oftentimes are unable to discern the root cause [82, 102]. As Black feminist thought and intersectionality attest to, Black women experience multiple forms of intersecting oppression such as racism and gender discrimination simultaneously, because race and gender cannot be separated for Black women. The conceptual glue in this situation appears to be that students have formed study groups based on shared racial identity rather than study groups composed of students who are taking the same classes regardless of racial identity. Nicole does not "fit" the category of "likeness" that will admit her into this resource of collaborative problem solving that she knows will help her to be successful in the CS course. Contrary to the misconception that Black women just need to make friends with other CS students to persist in the field [89], Nicole is subjugated to the margins, forced to study with other Black students in the course, if there are any, or on her own, further perpetuating the isolation that Black women report experiencing in CS departments at PWIs [82, 83, 102]. Nicole's testimony exemplifies that PWIs were not designed to serve the educational needs of non-White students. Instead of creating a learning environment that is more inclusive of different racial groups that interact with one another, the culture of PWIs upholds whiteness as the norm.

5.2.2 Jade's Testimony. In another example of PWIs as sites of violence, Jade, a current graduate student, shared her experience working with a group of three White males on a group project in an undergraduate $\mathrm{C}++$ programming class:

I had this one project where we were working with several other people on the project and I just don't like group projects in general (laughs), especially in undergrad. I really didn't like group projects...So it was this one project and I was working with three - three other boys and it was just a class that was so heavily filled with boys. It just so happened I was with three other boys and we were working on the project and we couldn't get it to work and I suggested approaching it in a different way and they were like no, no, no, no, no, no. And I was like okay, well, we can keep doing what you're doing, but I'm pretty sure 
this is not going to work. And like in my head, I knew the way they were trying to do it wasn't going to work, but I wanted to be a team player. I had done pitched something else and they said no. So I was like okay, but it was getting closer and closer to the deadline so I was like you know what, whatever. So I went home and I basically went - like recreated our project and did it all by myself, like the way I thought it would work. Then when I got it to work, I brought it back to the next team meeting we had, they were still struggling, trying to get their thing to work and I knew it wasn't going to work the way they were trying to do it, so I showed them what I did. And then they were like 'Oh my gosh, this is so great, this is so great. Why didn't we think of this the first time?' ...I was like 'Well, I tried to say it.' And I'm like 'Yeah, well, I tried to say we should take it this way' and then even then when I showed them something that was working, they were still like 'Oh, you know, yeah, this is kind of like what I said that one time.' And I'm like 'No, it's not (laughs). I'm not even going to let - I'm not going to let you do that.' But like that whole experience was really, really frustrating for me.

In this example, Jade does not know if this differential treatment is because of her race or her gender. Again, this represents a common conundrum that Black women in computing encounter on a regular basis. What Jade does know is that her White male peers do not value her as an equal contributor in this group assignment and dismiss her attempts to engage in collaborative problem solving, even after she articulates a potential solution. Despite Jade's efforts to be a team player, she is forced to work in isolation, and consequently, derives a working solution, which she then presents to her White male teammates. Upon verification that her solution works, one of her White male peers refuses to even give her credit for coming up with the working solution, co-opting her idea as his own invention. Black women deal with these kinds of microaggressions on a routine basis and can never discern if it is their gender or their race that causes their White male peers to dismiss them as being incompetent computer scientists.

In this scenario, the three White males hold power, not only by their numbers, but also by the dominant posture that they assume within the group. Power works within this scenario as the act of silencing Jade's ideas in what is supposed to be a collaborative programming assignment. Here, Jade experiences the intersecting oppression of race, gender, and perhaps class as perceived by her White male peers. The conceptual glue that binds the intersecting oppression of racism, sexism, and perhaps classism lies in the White males' assumption that Jade has nothing valuable to add to the conversation and cannot help the group in a meaningful way, particularly since the solution they originally came up with was not working. As such, she is subjugated to the margins of the group and is not allowed to participate fully in the collaborative problem-solving experience. In this scenario, we see how Jade resists subjugation, working alone to complete the programming assignment and then bringing her solution back to the group. Although the three White men recognize that her solution, which serves as an act of resistance, is correct, instead of accepting and acknowledging her as a fully capable and contributing member of the group, Jade is still pushed to the margin as one of the White males suggests that he gave her the idea. While her labor is accepted, Jade's full competency and expertise are not. She engages in resistance against this epistemic violence, yet it appears that the hearts and minds of her group members remain unchanged. As in other scenarios explored for this saturated site of violence, it is not clear whether she has received this treatment because of her race, gender, perceived class, or some other reason.

5.2.3 Keisha's Testimony. In multiple interviews, Black women discussed the challenges they encountered in graduate school at PWIs. Below, Keisha talked about not feeling welcome in the electrical and computer engineering department, a recognized area of study that falls under the category of computing. Keisha described the difficulty she encountered when trying to find research 
opportunities as a first-year graduate student before eventually choosing to leave the Master's degree program at the PWI.

Ijust didn't feel... didn't feel welcome, and so the change [the decision to leave the Master's program] was like a mix of things... So while I was there, I was really interested in robotics, and so there was one professor who did the robotics thing. He had the lab, and I realized that I really wasn't welcome, because other people were getting invited to join labs ... and do work with certain professors. Even though I had been doing research at the school since I got there, because I was in like a minority engineering program where they put you with different professors and you do work, and the professor - one professor that I had worked with, he got really ill, and then the other professor that I worked with was also my advisor, but he never actually invited me to join his lab when I started. So I was seeing other people getting invited into these labs, and I wasn't. I was like, okay, well, that kind of made me feel like well, maybe people just don't want me to work with them. Maybe they don't think I'm - you know, maybe they don't think I'm smart enough for - I don't know... I'm seeing other people being invited to labs to do work, and I wasn't... I didn't know how graduate school worked. Nobody actually told me. So I think some of it was, you know, I wasn't really kissing up to the right people like you're supposed to. If you want to work in a certain lab, and I didn't know that that was a thing that you had to do. I just thought, okay, if I take your class, if I do well, you know, if I'm telling you that I'm interested and I'm talking [to] you that that will get me an invite, and that just wasn't so. I think also with the person who I was working with not saying, 'Hey, well, if you're looking for a lab you can come over here.' With them not inviting me, I think maybe that signaled something else to other people in their labs that you know, maybe I'm not a good worker. So I'm not quite sure. I think, you know, part of it was lack of knowledge and then part of it was lack of knowledge; lack of it was me not having that, was me not having that - not really knowing - like not being a part of the "in" crowd, I guess, in electrical engineering at the school... My advisor, he did work in microelectronics. So I think just him not extending that invitation to me, him not putting his - sticking his neck out for me, which I think other people's advisors did do, that could have also put me in that position.

Despite the fact that Keisha has earned a Bachelor's degree in electrical engineering from the PWI, Keisha realizes that graduate school works very differently than the undergraduate CS program at the same PWI. She realizes that her alma mater is not so inviting for Black women interested in pursuing a graduate degree in electrical engineering or computer engineering. During her first attempt to complete a Master's level graduate program in the electrical and computer engineering department at the PWI, she learns that it is customary to "kiss up" to a research advisor in order to receive an invitation to work in his research lab rather than evaluating a student's academic performance, work ethic, or ability to do research as justification for being invited to work in someone's lab. Keisha has expressed a keen interest in doing robotics-related research and knows that her assigned faculty advisor does research in this area. (Robotics is considered a relevant subfield in computing.) Keisha has engaged in multiple conversations about doing research with her assigned advisor and other professors in the department, but no one extends an invitation to her to work in their labs. Despite being a member of the minority engineering bridge program, Keisha eventually discontinues the graduate program and leaves that particular PWI to enroll in the Master's program in CS at a HBCU. In this example, the cultural domain of power exhibited by male professors within the electrical and computer engineering department conveys the message that Black women are not welcome here. The combination of the department culture and interpersonal interactions with professors in the department create a hostile environment $[10,69]$ 
in which this Black woman is discouraged from completing an advanced degree despite having a B.S. in electrical engineering from the same department or expressing interests in robotics research being done in the same department, the typical prerequisites for engaging in research with faculty. Moreover, Keisha questions her level of intelligence and her ability to do graduate level work since her assigned advisor chooses not to offer any guidance or support to help her to understand the expectations and scholarly practices necessary for successfully obtaining a Master's degree.

Though Keisha's testimony is situated within an electrical and computer engineering department, the social dynamics would be relevant across multiple disciplines and subfields. However, Keisha's experience testifies to the unwelcoming culture attributed to many computing departments at PWIs [69]. The faculty member chooses to exercise his power and authority to advise non-Black students in the graduate program while offering no guidance about how to gain entry into his or any colleague's research lab even though this Black woman graduate student is his assigned advisee. In this scenario, racial and gender identities become a form of oppression that impedes navigating graduate school for Keisha, who is seeking research experience in robotics with any willing faculty member. She fails to understand the unspoken rules and norms in her department since she is relegated to the outer fringes. Here, the power rests with faculty who can choose whom they invite into their lab to work as graduate research assistants. Despite having expressed to the faculty member her desire to conduct research, Keisha finds herself without a research lab and no research advisor. The contrived nuances of power within and across the oppressive systems of racism, sexism, and ability (in terms of her perceived ability to conduct research) are such that Keisha does not receive an invitation to join any faculty member's lab, and she is unsure whether this is because of her race, gender, or perceived ability. The conceptual glue in this scenario appears to be that she is perceived as somehow deficient and not a good fit with the department culture. Therefore, Keisha is not encouraged to stay as evidenced by the lack of opportunity to engage in research with any faculty in the department of electrical and computer engineering.

The additional conceptual glue in this narrative is the unspoken norm that students should "kiss up" to faculty to receive invitations to join their labs. It is not clear what "kissing up" entails or who told her that "kissing up" was an unspoken norm required to receive lab invitations. However, what is clear is that she has not assimilated or behaved according to the department's cultural norms. Her perceived inappropriate behavior is also being surveilled by other faculty members in the department who are looking to the one faculty member who has had prior interactions with her to signal her "fitness" or worthiness. As such, Keisha is not only surveilled, she is, ultimately, perceived as unfit to do research, a critical skill for success in graduate school. Keisha resists this oppression by leaving this particular graduate program and resuming her graduate studies first at a HBCU for her Master's degree in computing technology and then later matriculating into a doctoral program in computing at a PWI. One thing is for certain: Keisha has experienced epistemic violence in a electrical and computer engineering department at a PWI, a saturated site of violence.

\subsection{Internships as Supplementary Learning Experiences to Post-Secondary CS Education}

While the traditional classroom environment largely contributes to CS education, internships supplement classroom instruction, providing opportunities for students to gain real-world experience applying computing concepts, principles, and skills to solve real-world problems. Unsurprisingly, students covet internships, because they acquire hands-on training and develop new skills that can be included on their resumes, giving them a competitive edge in the job market. Because internships are situated within a particular geographical location, students can appreciate work-life balance as they participate in local events and interact with residents of the community while learning on the job. We explore two Black women's internship experiences. 
5.3.1 Mercedes' Testimony. Excited about traveling to a different geographical location known for its abundance of tech companies and ethnic diversity of people, Mercedes described her summer internship experience as indicative of prejudice and gendered racism not only in the work environment but also in the surrounding community.

I never experienced so much prejudice on a day-to-day basis until I went away. And so getting stared at or wearing my hair unprocessed or, you know, just being a black woman. And it wasn't even just the institution where I was interning. It was the actual community that we lived in, you know? Looking at us funny, like, 'Oh, there's black people here.' Like I mean yeah. And I'm not ratchet, I'm not from the hood. I'm very well educated. And they just couldn't believe it, you know. It's like people would ask, walk up to me like 'What are you doing here?' 'Um, working.' (laughs) 'Where do you work at? Where do you work at?' I said, 'Oh, I work such and such lab.' 'Really?' You know, like shocked. Like 'I can't believe this, like an educated black woman.' (laughs) ... I had my naïve impression ... But I mean at the institution itself, you know, getting those funny stares, people looking at you funny, people treating you like you're different, and you start to feel like you're different. And if you're not careful you'll think less of yourself... I found myself getting really, really shy...very cliquish with the other black interns, you know... When I'm dealing with someone who's not black at work there's always this thought in the back of my mind that they're going to look at me differently, and they have the potential to treat me differently because of what I look like... I literally, like I heard this young white boy, and he was interning there with us from like one of the high schools. He was telling black jokes with another intern...I mean he's young and stupid so I mean it pissed me off but that was one of those things I kind of just had to rise above, and it's like 'You know what? Go on back in your office and shut the door'... It wasn't the fact that he said it. It was the fact that he said it at work.

Mercedes was disappointed to find this particular diverse geographical location to be hostile to Black women since people of different nationalities and ethnicities live and work there. The stares and questions from local inhabitants, indicative of the interpersonal domain of power, implied that Black women, regardless of educational background or socioeconomic status, were an anomaly and did not belong in this professional laboratory or predominantly White community. Black women, despite being American citizens, often experienced differential treatment from both professional peers and fellow American citizens. In this way, the internship experience, representative of being out in the world, became a site of oppression in which Black women were accosted because of racial differences.

Mercedes experiences the ramifications of power as she interacts with people who are residents of the city where her internship is held. In this case, local residents hold power because of their knowledge of the city and understanding of the social and cultural norms. Oppressive systems of racism, sexism, and perhaps perceived classism are made visible in the way she is spoken to, the comments people make about her showing up as her authentic self with her natural hair, and the looks she receives as she navigates the city and interacts with its residents, who are diverse, but are not Black women. The conceptual glue that binds the intersecting systems of racism, sexism, and perhaps perceived classism and ability are notions of this Black woman as exotic, other, or "ratchet" as she wears her natural hair, and assumptions that she resides in the city in some other capacity other than working as a summer intern. This is evidenced by the surprise or disbelief that the residents express once they learn that Mercedes is working for this company, also suggesting that she lacks the proper credentials (i.e., college education and qualifications) to work for this company. Residents' low expectations of Black women and subsequent surprise when it is discovered that 
they have advanced college degrees or work in high-tech environments where one must possess specialized knowledge and skills to be employed are common phenomena that Black women in computing experience $[32,102]$.

Mercedes is surveilled by the residents, not only with their eyes as they stare at her, but also through their interrogation of her whereabouts and motivations for being in the city. This practice of surveillance has a long, sordid history in the U.S. when Black people were required to account for their whereabouts at any moment when questioned by White people [53]. For example, during slavery, Black Americans had to produce "papers" giving them permission to leave the plantation or manumission "papers" stating they were free persons of color [53]. During the Jim Crow era Black Americans had to leave the jurisdiction of towns, particularly those in rural areas, before sunset to avoid being subjected to physical harm in what became known as "sundown towns" [53]. Likewise, subjected to constant surveillance, Mercedes realizes that the city's inhabitants consider Black women to be foreigners and unwelcome visitors. Mercedes demonstrates an awareness of the surveillance that Black people endure in the description of herself as "not ratchet," "not from the hood," and "very well-educated," alluding to the fact she is a "respectable" Black person. Respectability amongst Black people is when there is an attempt to confirm that one's background and personal values align with the dominant culture (whiteness) as a reason why they should be deemed acceptable $[45,54]$. This is an example of why the notion of respectability is problematic for Black people, because despite the things that one may think hinders full acceptance into white society (e.g., class, education), many Black people still face challenges [54].

Mercedes also encounters racism in the workplace when a fellow White male intern decided to tell "black jokes" to another male intern. In this scenario, the White male intern holds power as he uses his racial identity to verbally abuse Black people in the workplace, feeling no need to censor himself as he tells derogatory jokes that denigrate Black people. Racism and sexism mutually influence one another to uphold White supremacy and patriarchy as witnessed by Mercedes when the White male intern tells a "black joke" to another male employee. It is not clear if the intern knew that Mercedes had overheard him telling the joke. However, psychological violence is inflicted on Mercedes because the act of telling "black jokes" denies the humanity of Mercedes and other Black Americans who work at that respective company. Within the confines of the workplace, the conceptual glue that binds the oppressive forces of racism and sexism together is the freedom and privilege that the White male interns enjoy because the majority of employees are White men and the company culture upholds White men as the typical model employee. Technology continues to be a male dominated field that upholds whiteness with the continued under-representation of women, Black Americans, Latinx, Native Americans, Pacific Islanders and other indigenous populations as indicated by the lack of inclusion of historically excluded populations at most tech companies $[50,98]$. Suffering from emotional trauma, Mercedes feels powerless to do anything about her fellow interns' behavior since he perceives telling black jokes as acceptable behavior at work, so she retreats to her office to deal with her anger and compose herself. Mercedes' worst fears of being treated differently because she is a Black woman manifest themselves in the context of her summer internship experience.

Internships provide an environment where students, as interns, can apply the concepts they learn at their respective institutions to solve real-world problems and gain valuable work experience while establishing professional networks with full-time employees and the cohort of other interns (students) working temporarily for the company. These internship experiences are typically designed to give interns exposure to the city where the company is located, helping interns to experience the city by living there temporarily to assess whether the city and its people are a good fit for full-time employment. Unfortunately, for Mercedes, the internship experience becomes a saturated site of violence both inside and outside of the workplace. Given these 
violent experiences, Mercedes decides not to pursue another internship opportunity with this company.

5.3.2 Taylor's Testimony. Like many graduate students, Black women look for opportunities to explore career options to give them a competitive edge in the job market. Such experiences influence students' decisions to pursue careers in academia versus industry. Having secured employment in industry, Taylor recalled her experience working as an intern one summer in between semesters.

There was a guy on my team. He was very difficult to work with. He was another intern, and he was - I think he was a mechanical engineer, but he was an Asian guy and he was very sure of himself, but he didn't have any experience doing any type of user-centered design, product development, anything like that. And so a lot of times when I was working on teams of interns, because the other interns may be undergraduate students and I was a Ph.D. student, or because I had experience with user-centered design principles and a product development background and things like that, I always seemed to emerge as a leader on the team. But this particular young man had difficulty accepting that I was in charge, and so he would do things like question me when I knew what I was talking about or try to go behind my back - And he just didn't listen well [...] it's just this idea of why do I have to be the only person on this team that has to prove themselves before I start earning the respect that I'm supposed to be given or that everyone else is given. If everyone had to prove themselves from the beginning, I would be totally fine with that, but if I'm the only one that has to prove myself, then that's a problem.

Taylor describes how her Asian fellow intern did not value her leadership skills or her prior professional work experience. Instead of perceiving her prior work experience in user-centered design and product development as an asset to the team, he exercises his privilege to question her ability to lead the team and refuses to recognize her as a leader. While this behavior could be a symptom of gender discrimination more so than racism, but again as in previous scenarios, the root cause is unclear. Either way, this is an example of gendered racism, and her colleague's constant questioning and pushback create an oppressive work environment for this Black woman.

In this scenario, Taylor experiences the nuances of power in the workplace, where she is interacting with another intern who happens to be an Asian male. We see a rare example of a Black woman who does have some power in the context of her fellow interns. During the internship, Taylor is a Ph.D. candidate with previous work experience that is relevant to her current internship. She serves in leadership positions on different projects as a result of these life experiences. However, her Asian male colleague constantly challenges her right to power and attempts to undermine her leadership despite her having more work experience and training. The conceptual glue that binds the intersecting systems of racism, sexism, and her ability to perform her job lie in the Asian male's assumption that although Taylor has more education and work experience than he does, she must repeatedly prove her competence to his satisfaction. His attitude conveys the message that Taylor has no right to tell him what to do or govern his actions or work in any way. The Asian male surveils Taylor in an attempt to subvert her leadership while relegating her to the margins by not listening, acknowledging, or respecting her leadership. Taylor's perception that she is the only one who has to prove herself over and over suggests that his rejection and subjugation of her is effective to some extent. Further, it is not clear to her whether these microaggressions are because of her gender, race, perceived class, or ability. It is also not clear whether she, ultimately, resists, but she does make note of the lack of consistency and equity in this situation, since she is the only person who has to prove themselves and their competency over and over. Black women 
in computing have reported this constant proving of competency in the workplace as a common occurrence, sometimes happening over a number of years [102].

5.3.3 Kennedy's Testimony. Black feminist thought invokes resistance as a means of survival, including Black women who struggle to persist in the field of computing. Kennedy, a tenure-track faculty member, reflected on her experiences as both a student and a computing professional. She succinctly states the obvious:

You got to get thick skin because you're going to have to be able, uhm, to bypass any aggressions, whether they be micro or macro and - because they're coming and they're not going to go away, and if you can't focus yourself and you get easily distracted by those kinds of things, you're done. You're done. Right? Uhm... Because a lot of it is about self-motivation. You're going to be in a lot of spaces where it's going to be uncomfortable. You're going to be alone. You're going to uhm be marginalized. You're going to be considered less than. And so if you don't have good coping strategies, then it's going to be really hard. The sooner you develop those coping strategies, the better.

What becomes apparent in Kennedy's summation of her lived experiences is that Black women endure violence on multiple levels throughout the computing ecosystem, whether they are students in CS K-12 classrooms, undergraduate or graduate students at PWIs, or early career professionals in industry or academia. She has learned that CS education and computing, more broadly, are rife with systemic racism and sexism and, consequently has learned to adapt ("get thick skin") and survive ("bypass any aggressions") in these hostile environments. Because of these endless attacks, Kennedy advises Black women to develop coping strategies for surviving these attacks on their humanity, computing competency and right to exist as legitimate members in the field of computing. She understands that violence is inevitable and so Black women must develop "good coping strategies" as soon as possible to increase the retention of Black women in computing. One such coping strategy is self-motivation, which keeps Kennedy focused on the longterm goal of persistence in computing. Kennedy's reflection is a testimony of the determination and resiliency of Black women in computing who engage in acts of resistance, refusing to be defeated by systemic racism and sexism, the conceptual glue that enables the continued oppression of Black women.

Kennedy's testimony serves as a reminder that Black women suffer multiple forms of violence just to succeed in the field of computing. Though Kennedy has the intention of dispensing survival tips to Black women in computing, this places the ownership of dealing with the impact of violence on Black women, rather than working to dismantle these structures of oppression. Given the racial disparities evident in women's health, Black women's bodies can no longer afford to pay the high price of emotional turmoil and weathering, the chronic stress of consistently dealing with racism and sexism on a regular basis, which contributes to poor health outcomes [97, 102].

In summary, we appreciate every Black woman that willingly shared her experiences, recognizing that doing so often resurrects feelings of frustration, anger, impotency, and trauma associated with these violent acts. As evident in Kennedy's testimony, Black women in computing often develop necessary coping strategies to successfully navigate traditional classroom settings, predominantly White institutions and internships that supplement post-secondary education. These coping strategies represent acts of resistance that enable Black women to survive.

\section{DISCUSSION}

As an act of resistance to the social injustices prevalent in the field of computing, Black women scholars have begun to identify and examine saturated sites of epistemic violence in CS 
education designed to oppress Black women. Our lived experiences navigating the field of computing shed light on how systemic racism and other forms of discrimination contribute to the hostile and toxic environments that preclude Black women's struggle to not only survive, but to thrive in this male-dominated field. Leveraging the testimonial authority of Black women, born out of their unique outsider-within vantage point within CS [16], our analysis reveals several insights.

\subsection{Epistemic Violence in CS Education is Constant and Can Occur at Every Level, Academically, Personally, and Professionally, on Many Different Fronts for Black Women}

Referring specifically to Aaliyah's experience of enduring cold temperatures in her first CS course (physical violence), the pressure to assimilate begins in the high school classroom, relegating Black girls to the margins of CS education where they are expected to suffer in silence (psychological violence) and not exercise their agency to ask questions or satisfy their own intellectual curiosity. The attack continues onto the campuses of predominantly White colleges and universities and moves with Black women into the undergraduate and graduate CS classrooms where they are surveilled, subjugated, ignored, and continuously pressured to behave like stereotypical White male computer scientists who dream in code, are socially inept, and have no life beyond computers (psychological violence) $[66,67]$. While the stereotype of White males as typical computer scientists is false, so are the stereotypes of how Black women should behave or what Black women should look like (i.e., Mercedes receiving stares because she wears a natural hairstyle rather than straightening her hair) to be accepted into the field. Subliminal messages of inferiority and deficiency exist in personal interactions with classmates and faculty inside and outside of the classroom such as those experienced by Keisha when she sought research opportunities in a faculty member's research lab. Anti-black racism exists in the spaces where Black women live during their internship experiences as well as on the job where they work for computing companies, both from their peers as well as within company cultures (i.e., violence disguised as humor when the White male intern tells "black jokes" to his male colleague). What is clear from the testimonies of Black women in various stages of the computing ecosystem is that saturated sites of violence are everywhere in CS education, and Black girls and women are constantly under siege without a moment's rest anywhere, except, perhaps among family members as discussed in Rankin et al. [82] and Thomas et al. [102]. It is no wonder that we see the recent uprise, a demand for justice largely led by Black women, within the field of computing [29, 44, 73, 81].

\subsection{CS Education is not a Colorblind Meritocracy; It is a Matrix of Intersecting Oppressions for Black Women in Computing}

Computing as a field represents a system. The concept of a system is a foundational and important concept in CS education. The way systems form, how they function, their outcomes, economies, components, and other aspects of systems and systems thinking undergird the field. We must apply that same understanding and rigor, in coalition and relationship with historically excluded groups who experience and contend with these systems each day, if we aim to better understand and, ultimately, dismantle the systems and structures that have yielded the saturated sites of violence in CS education described in this article and other sites that have yet to be discovered. As such, when we consider transforming CS education, we must begin to think about that transformation, at the interpersonal level as well as at the systemic level as both are required for true transformation of the field. This article has served as an initial step at uncovering the structures, and we charge the field to begin to think about structural changes that can make CS, as a field, more equitable and 
just. These findings point to patterns within the field of CS education that reveal repeated sites of violence, a notable finding for a field that claims to be a meritocracy and colorblind.

\subsection{Black Women May be Exiting the Field of Computing as a Form of Resistance}

According to data collected from the 2012 Higher Education Research Institute (HERI) [51], Black women enter their undergraduate years with the highest intent to major in CS than any other group. However, prior research shows that Black women are among the most marginalized populations when it comes to obtaining Bachelors, Masters, and Ph.D.'s in computing [61, 110-112]. What is happening once Black women enter college? Results from our study suggest that Black women are contending with these saturated sites of epistemic violence on all fronts and, in some cases, avoiding CS courses in college (Aaliyah's experience) or choosing to withdraw from graduate programs (Keisha's experience) as an act of resistance. While additional research needs to be done to explore the ways in which Black women in computing resist oppression, it is certainly logical to consider that exiting the field could be seen, not as a signal that Black women do not possess enough grit or are incapable, but rather, as a form of resistance to surveillance, subjugation to the margins, and assimilation that was repeatedly reported by the Black women in our study.

In response to these saturated sites of violence in CS education, we reject this notion of a homogeneous population of "women of color" and call for the community of researchers to build coalitions with Black, Latina, Native American, Asian, and Pacific Islander women scholars who do this work within their communities as a step toward understanding the particular "power grid" or matrix of intersecting power dynamics that impact each of these groups. This suggests that, within CS education, we also need to think about developing new theories, methods, and approaches to engage, understand, and support historically excluded groups as they contend with their particular systemic configuration of saturated sites of epistemic violence.

\subsection{Examining the Conceptual Glue that Uncovers Assumptions about How Students Enter and Navigate Through CS Education is Important in Understanding the Systems and Structures that Black Women Contend with as Evidenced by these Saturated Sites of Epistemic Violence}

Collins [17] asserts that this conceptual glue"binds intersecting systems of power together" (p. 238). We posit that this conceptual glue consists of the assumptions and dominant narratives that have been constructed and told to the field of computing. In addition, these assumptions and narratives are used to tell stories about why things in CS education are the way that they are. They are the mechanisms through which epistemic violence is justified and, "as a constellation of practices, violence is also essential to organizing and managing power as domination” (ibid.). Collins also contends that "the routinized and normalized nature of violence, and the mechanisms that legitimize this entire endeavor from within distinctive systems of power become more visible within frameworks that see violence as one node of the connective tissue of systems of power" (ibid.). Our intersectional analyses have been leveraged to make more visible the connective tissue of systems of power in CS education as Black women have described experiencing them in their own words. Again, a call to action by the field to build coalitions with Black women and stay in community with Black women in computing is needed to uncover and understand additional saturated sites of epistemic violence within the field.

Further analysis is needed for identifying additional sites of violence in CS education since this article introduces this concept and identifies only three sites of violence. We do not assume that these three sites are the only ones that exist in CS education or the field more broadly. Future work includes continuing to expand the scope of our analysis to identify additional sites of violence in the CS ecosystem. 


\section{CONCLUSION}

An emphasis on policy (requiring students to take CS courses in high school to fulfill graduation requirements) alone will not address the system of intersecting oppression if White teachers who are teaching Black students bring deficit-model thinking and other biases to the classroom and subsequently, treat Black students disparagingly [28]. Furthermore, statistics of how many students of color take the AP CS exam does not tell us if predominantly Black schools have the same resources as students in predominantly White, more affluent schools or neighborhoods [30].

Comparing the elitist structure of computing to the field of health sciences actually provides a model of what's possible for us as a field. In health sciences, core courses may include biology, health informatics, environmental health, physiology, chemistry, and so on, indicating the breadth of curriculum that is customized based upon selection of a specific health profession. For example, the field of health sciences includes doctors, nurses, dentists, pharmacists, nutritionists, physical therapists, chiropractors, and so on. A health science major may choose to take courses that prepare her for a career as a health informatics professional while another student may choose the career path of medical doctor and major in biology or chemistry. Students can pursue an Associate's degree, a Bachelor's degree, or more advanced degrees in the health sciences and still enjoy an economically viable career in the health sciences. There is no explicit preferred path for pursuing a career in the health sciences as there are multiple paths and degree options for attaining a degree in the health sciences. Furthermore, students are not expected to have significant experience in the health sciences prior to matriculation into college. Instead, STEM departments provide supplementary resources (e.g., summer bridge programs for incoming freshman students, free tutorial sessions, copies of old exams, lecture notes, teacher assistants) to help students get up to speed and meet department expectations for health sciences majors. The field of health sciences has less restrictive entry points or barriers and more readily available resources (e.g., lab kits for dissecting specimens in an entry-level biology course) to all students for pursuing a career as a health science professional. Given the multiple paths into health science and abundance of resources, more students of color attain degrees in the health sciences [31]. This is not to say that the field of health sciences does not face its own challenges with structural and/or gendered racism. However, barriers of entry appear to be fewer.

Turning a critical eye to the field of computing, it is essential that those who wield and benefit from power do the work of dismantling these oppressive systems. If historically excluded and marginalized groups such as Black women understood how these structures were configured and designed to operate, we would have dismantled these systems long ago. However, we did not build these systems. As we engage and act in coalition, we may discover that neither those who benefit nor those who are marginalized understand how these oppressive structures were designed. However, through coalition and by staying in relationship, we can continue to make visible the structures and the design of the system, and we can figure out ways to dismantle it and replace it with systems that yield more just and equitable outcomes. That will require three things on the part of those who configured, designed, and/or benefit from the structures and systems. First, they must be comfortable with relinquishing power and/or the benefits that they derive from it. Second, they must be committed to the work of being both reflective and reflexive, questioning every assumption and asking why is it that way, where did that assumption come from, who it benefits and who it harms. Finally, they must be committed to doing the work that is theirs alone in dismantling the system. Marginalized groups may not be able to tell you how to dismantle the system, and they should not be expected to bear the burden and labor of dismantling the system, given the work they already have to engage in contending with the saturated sites of violence that have begun to be uncovered in this article. In essence, let us work together to build coalitions and transform computing education into a field and space that is just and welcoming to everyone. 


\section{REFERENCES}

[1] Olugbenga Ajilore. 2019. 3 Ways to Improve the Outcomes for African Americans in the Rural South. https:// www.americanprogress.org/issues/economy/reports/2019/08/06/470913/3-ways-improve-outcomes-africanamericans-rural-south/.

[2] April Alvarez, Legand Burge, Shameeka Emanuel, Ann Gates, Sally Goldman, Jean Griffin, Harry Keeling, Mary Jo Madda, Bianca Okafor, Alycia Onowho, and Gloria Washington. 2020. Google tech exchange: An industry-academic partnership that prepares Black and lLatinx undergraduates for high-tech careers. fournal of Computing Sciences in Colleges 35, 10 (April 2020), 46-52.

[3] Computer Science Teachers Association. 2017. CSTA K-12 Computer Science Standards, Revised 2017. Retrieved November 18, 2020 from http://www.csteachers.org/standards. http://www.csteachers.org/standards.

[4] Jon Beck. 2007. Forming a women's computer science support group. In Proceedings of the 38th SIGCSE Technical Symposium on Computer Science Education (SIGCSE'07). Association for Computing Machinery, New York, NY, 400-404. https://doi.org/10.1145/1227310.1227451

[5] bell hooks. 1984. Feminist Theory: From Margin to Center. South End Press, Boston.

[6] bell hooks. 1989. Talking Back: Thinking Feminist, Thinking Black. South End Press, Boston.

[7] Quincy Brown. 2020. “On Being Black in Computing During These Days.” https://medium.com/@quincykbrown/onbeing-black-in-computing-during-these-days-54e049d56987.

[8] Tracy Camp. 1997. The incredible shrinking pipeline. Communications of the ACM 40, 10 (Oct. 1997), 103-110. https: //doi.org/10.1145/262793.262813

[9] Devon W. Carbado. 2013. Colorblind intersectionality. Signs: Journal of Women in Culture and Society 38, 4 (2013), 13-19.

[10] Sapna Cheryan, Sianna A. Ziegler, Amanda K. Montoya, and Lily Jiang. 2017. Why are some STEM fields more gender balanced than others? Psychological Bulletin 143 (2017), 1-35.

[11] Raj Chetty, Nathaniel Hendren, Maggie R. Jones, and Sonya Porter. 2020. Race and economic opportunity in the United States: An intergenerational perspective. Quarterly fournal of Economics 135, 2 (2020), 711-783.

[12] Rosalind Chou and Joe R. Feagin. 2008. Myth of the Model Minority: Asian Americans Facing Racism (2nd ed.). Taylor \& Francis, UK.

[13] Code.org, CSTA, and ECEP. 2019. State of Computer Science Education. https://advocacy.code.org/2019_state_of_cs. pdf.

[14] J. McGrath Cohoon. 2002. Recruiting and retaining women in undergraduate computing majors. SIGCSE Bulletin 34, 2 (June 2002), 48-52. https://doi.org/10.1145/543812.543829

[15] The Combahee River Collective. 1977. The Combahee River Collective Statement: Black Feminist Organizing in the Seventies and Eighties.

[16] Patricia Hill Collins. 2000. Black Feminist Thought. Routledge, New York, NY.

[17] Patricia Hill Collins. 2019. Intersectionality as Critical Social Theory. Duke University Press, Durham, NC.

[18] Patricia Hill Collins and Sirma Bilge. 2016. Intersectionality. Polity Press, Cambridge, UK.

[19] A. Creighton. 2020. Dear Black Men, ALL Black Lives Matter. https://medium.com/@onlyoneaaronde/dear-blackmen-all-black-lives-matter-560c6b304a16.

[20] Kimberle Crenshaw. 1989. Demarginalizing the intersection of race and sex: A black feminist critique of antidiscrimination doctrine, feminist theory and antiracist policies. University of Chicago Legal Forum 1989, 1 (1989), $139-167$.

[21] Kimberle Crenshaw. 1993. Demarginalizing the Intersection of Race and Sex: A Black Feminist Critique of Antidiscrimination Doctrine, Feminist Theory and Antiracist Politics. University of Chicago Legal Forum 1989, 1 (1989), 383-395.

[22] Kimberle W. Crenshaw. 1995. Mapping the margins: Intersectionality, identity politics, and violence against women of color. In Critical Race Theory, Kimberle W. Crenshaw, Neil Gotanda, Gary Peller, and Kendall Thomas (Eds.). The New Press, New York, 357-383.

[23] Teresa Dahlberg, Tiffany Barnes, Kim Buch, and Audrey Rorrer. 2011. The STARS alliance: Viable strategies for broadening participation in computing. ACM Transations on Computing Education. 11, 3 (Oct. 2011), Article 18, 25 pages. https://doi.org/10.1145/2037276.2037282

[24] Richard Delgado and Jean Stefancic. 1997. Critical White Studies: Looking Behind the Mirror. Temple University Press, Philadelphia, PA.

[25] Robin DiAngelo. 2018. White Fragility: Why It's so Hard for White People to Talk about Racism. Beacon Press, Boston, MA.

[26] Kristie Dotson. 2011. Tracking epistemic violence, tracking practices of silencing. Hypatia 26, 2 (2011), $236-257$. https://doi.org/10.1111/j.1527-2001.2011.01177.x

[27] Angela Duckworth and Angela Duckworth. 2016. Grit: The Power of Passion and Perseverance. Vol. 234. Scribner, New York, NY. 
[28] Tisha Lewis Ellison. 2017. The matter in parents' stories: African American urban mothers' counter stories about the Common Core State Standards and quality teaching. Urban Education (2017), 1-31.

[29] Sheena Erete, Yolanda Rankin, and Jakita Thomas. 2021. I can't breathe: Reflections from black women in CSCW and HCI. In Proceedings of the ACM on Human-Computer Interaction, Issue CSCW (2021).

[30] Barbara Ericson and Tom McKlin. 2018. Helping underrepresented students succeed in AP CSA and beyond. In Proceedings of the 49th ACM Technical Symposium on Computer Science Education (SIGCSE'18). Association for Computing Machinery, New York, NY, 356-361. https://doi.org/10.1145/3159450.3159517

[31] National Science Foundation. National Center for Science and Engineering Statistics. 2019. Women, Minorities, and Persons with Disabilities in Science and Engineering: 2019. Special Report NSF 19-304. Retrieved August 26, 2020 from https://www.nsf.gov/statistics/wmpd.

[32] Kapor Center for Social Impact. 2017. Tech Leavers Study: A First-of-Its-Kind Analysis of Why People Voluntarily Left Jobs in Tech. http://www.kaporcenter.org/wp-content/uploads/2017/08/TechLeavers2017.pdf.

[33] Carol Frieze, Orit Hazzan, Lenore Blum, and M. Bernardine Dias. 2006. Culture and environment as determinants of women's participation in computing: Revealing the "Women-CS Fit". SIGCSE Bulletin 38, 1 (March 2006), 22-26. https://doi.org/10.1145/1124706.1121351

[34] Paula Gabbert and Paige H. Meeker. 2002. Support communities for women in computing. SIGCSE Bulletin 34, 2 (June 2002), 62-65. https://doi.org/10.1145/543812.543832

[35] Vashti Galpin. 2002. Women in computing around the world. SIGCSE Bulletin 34, 2 (June 2002), 94-100. https://doi. org/10.1145/543812.543839

[36] Patrica Garcia and Kimberly Scott. 2016. Traversing a political pipeline: An intersectional and social constructionist approach toward technology education for girls of color. InterActions: UCLA fournal of Education and Information Studies 12, 2 (2016), 1-26.

[37] Seth Gershenson, Stephen B. Holt, and Nicholas W. Papageorge. 2016. Who believes in me? The effect of studentteacher demographic match on teacher expectations. Economics of Education Review 52 (2016), 209-224. https://doi. org/10.1016/j.econedurev.2016.03.002

[38] Joanna Goode, Jane Margolis, and Gail Chapman. 2014. Curriculum is not enough: The educational theory and research foundation of the exploring computer science professional development model. In Proceedings of the 45th ACM Technical Symposium on Computer Science Education (SIGCSE'14). Association for Computing Machinery, New York, NY, 493-498. https://doi.org/10.1145/2538862.2538948

[39] A. H. Gupta. 2020. Why Aren't We All Talking About Breonna Taylor? https://www.nytimes.com/2020/06/04/us/ breonna-taylor-black-lives-matter-women.html?fbclid=IwAR1LtIepvJlH0QOEMGyXSdJzX3geSUgl5FFD4xSSzaXG sY_C2AmyDEYgPQI.

[40] Denise Gürer and Tracy Camp. 2002. An ACM-W literature review on women in computing. SIGCSE Bulletin 34, 2 (June 2002), 121-127. https://doi.org/10.1145/543812.543844

[41] Mark Guzdial. 2020. CS Teachers, It's (Past) Time To Learn About Race. https://cacm.acm.org/blogs/blog-cacm/ 245408-cs-teachers-its-past-time-to-learn-about-race/fulltext\#comments.

[42] Angela Hanks, Danyelle Solomon, and Christian E. Weller. 2018. Systematic Inequality: How America's Structural Racism Helped Create the Black-White Wealth Gap. https://www.americanprogress.org/issues/race/reports/2018/02/ 21/447051/systematic-inequality/.

[43] Sandra G. Harding. 2004. The Feminist Standpoint Theory Reader.

[44] Christina Harrington, Yolanda Rankin, Jasmine Jones, Robin Brewer, Sheena Erete, Tawanna Dillahunt, and Quincy Brown. 2020. A Call to Action for the ACM. http://interactions.acm.org/blog/view/a-call-to-action-for-the-acm.

[45] Paisley Jane Harris. 2003. Gatekeeping and remaking: The politics of respectability in African American women's history and Black feminism. Journal of Women's History 15, 1 (2003), 212-220.

[46] Jeet Heer. 2016. How the Southern Strategy Made Donald Trump Possible. https://newrepublic.com/article/130039/ southern-strategy-made-donald-trump-possible.

[47] Apriel K. Hodari, Maria Ong, Lily T. Ko, and Rachel R. Kachchaf. 2014. New Enactments of Mentoring and Activism: U.S. Women of Color in Computing Education and Careers. Association for Computing Machinery, New York, NY, 83-90. https://doi.org/10.1145/2632320.2632357

[48] Apriel K. Hodari, Maria Ong, Lily T. Ko, and Janet Smith. 2015. Enabling courage: Agentic strategies of women of color in computing. In Conference Proceedings of 2015 Research in Equity and Sustained Participation in Engineering, Computing, and Technology (RESPECT'15) 1, 1-7. 10.1109/RESPECT.2015.7296497

[49] A. K. Hodari, M. Ong, L. T. Ko, and J. M. Smith. 2016. Enacting agency: The strategies of women of color in computing. Computing in Science Engineering 18, 3 (2016), 58-68. https://doi.org/10.1109/MCSE.2016.44

[50] Sam Huisache. 2020. 2020 People of Color in Tech Report. https://www.trustradius.com/vendor-blog/people-ofcolor-in-tech-report. 
[51] Sylvia Hurtado, Kevin Eagan, John H. Pryor, Hannah Whang, and Serge Tran. 2012. Undergraduate teaching faculty: The 2010-2011 HERI faculty survey. Higher Education Research Institute: University of California, Los Angeles.

[52] Google Inc. and Gallup Inc. 2016. Computer Science Learning: Closing the Gap: Black Students. Technical Report. Issue Brief No. 2. Retrieved from https://goo.gl/FIhXKp.

[53] Elliot Jaspin. 2008. Buried in the Bitter Waters: The Hidden History of Racial Cleansing in America. Basic Books, New York, NY.

[54] Ibram X. Kendi. 2019. How to be an Antiracist. One World, Random House, New York.

[55] Neha Kumar and Naveena Karusala. 2019. Intersectional computing. Interactions 26, 2 (Feb. 2019), 50-54. https://doi. org $/ 10.1145 / 3305360$

[56] Richard Ladner. 2009. Experiences of students with disabilities in computing. fournal of Computing Sciences in Colleges 25, 1 (Oct. 2009), 114-115.

[57] Richard E. Ladner and Maya Israel. 2016. "For all" in "computer science for all". Communications of the ACM 59, 9 (Aug. 2016), 26-28. https://doi.org/10.1145/2971329

[58] Gloria Ladson-Billings. 1995. But that's just good teaching! The case for culturally relevant pedagogy. Theory Practice 34 (1995), 159-165. https://doi.org/10.1080/00405849509543675

[59] Gloria Ladson-Billings and William F. Tate. 1995. Towards a critical race theory of education. Teachers College Record 97, 1 (1995), 47-67.

[60] Stacy J. Lee. 2009. Unraveling the Model Minority Stereotype: Listening to Asian American Youth (2nd ed.) Teachers College Press, New York, NY.

[61] K. J. Lehman, L. J. Sax, and H. B. Zimmerman. 2017. Women planning to major in computer science: Who are they and what makes them unique? Computer Science Education 26, 4 (2017), 277-298.

[62] Audre Lorde. 1984. Sister Outsider: Essays and Speeches. Crossing Press, Trumansburg, NY.

[63] Stephanie Lunn, Leila Zahedi, Monique Ross, and Matthew Ohland. 2021. Exploration of intersectionality and computer science demographics: Understanding the historical context of shifts in participation. ACM Transactions on Computing Education 21, 2 (March 2021), Article 10, 30 pages. https://doi.org/10.1145/3445985

[64] Vanessa Patino Lydia and Vinessa Gordon. 2021. Sounding the Alarm: Criminalization of black girls in Florida.

[65] Lindsey Malcom and Shirley Malcom. 2011. The double bind: The next generation. Harvard Educational Review 81, 2 (2011), 162-172.

[66] Jane Margolis, Rachel Estrella, Joanne Goode, Jennifer J. Holme, and Kimberly Nao. 2017. Stuck in the Shallow End: Education, Race, and Computing. MIT Press, Cambridge, MA.

[67] Jane Margolis and Allan Fisher. 2002. Unlocking the Clubhouse: Women in Computing. MIT Press, Cambridge, MA.

[68] Jane Margolis, Joanna Goode, Gail Chapman, and Jean J. Ryoo. 2014. That classroom 'magic'. Communications of the ACM 57, 7 (July 2014), 31-33. https://doi.org/10.1145/2618107

[69] Allison Master, Sapna Cheryan, and Andrew N. Meltzoff. 2016. Computing whether she belongs: Stereotypes undermine girls' interest and sense of belonging in computer science. Journal of Educational Psychology 108 (2016), 424-437.

[70] Peggy McIntosh. 1989. White privilege: Unpacking the invisible knapsack. Peace and Freedom (1989), 10-12.

[71] Terrell R. Morton and Eileen C. Parsons. 2018. \#BlackGirlMagic: The identity conceptualization of Black women in undergraduate STEM education. Science Education 102, 6 (2018), 1363-1393. https://doi.org/10.1002/sce.21477 arXiv:https://onlinelibrary.wiley.com/doi/pdf/10.1002/sce.21477.

[72] Esme Murphy. 2020. “I Can't Breathe!”: Video of Fatal Arrest Shows Minneapolis Officer Kneeling On George Floyd's Neck for Several Minutes. https://minnesota.cbslocal.com/2020/05/26/george-floyd-man-dies-after-being-arrestedby-minneapolis-police-fbi-called-to-investigate/.

[73] Ihudiya Finda Ogbonnaya-Ogburu, Angela D. R. Smith, Alexandra To, and Kentaro Toyama. 2020. Critical race theory for HCI. In Proceedings of the 2020 CHI Conference on Human Factors in Computing Systems (CHI'20). Association for Computing Machinery, New York, NY, 1-16. https://doi.org/10.1145/3313831.3376392

[74] Charles J. Ogletree. 2004. All Deliberate Speed: Reflections on the First Half Century of Brown v. Board of Education. WW Norton \& Company.

[75] Maria Ong, Carol Wright, Lorelle L. Espinosa, and Gary Orfield. 2011. Inside the double bind: A synthesis of empirical research on undergraduate and graduate women of color in science, technology, engineering, and mathematics. Harvard Educational Review 81, 2 (2011), 172-208.

[76] R. A. Oppel and D. B. Taylor. 2020. Here's What You Need To Know About Breonna Taylor's Death. https://www. nytimes.com/article/breonna-taylor-police.html.

[77] Fay Cobb Payton. 2014. Leveraging Intersectionality: Seeing and Not Seeing. Richer Press, Arizona.

[78] Bree Picower. 2009. The unexamined whiteness of teaching: How white teachers maintain and enact dominant racial ideologies. Race Ethnicity and Education 12, 2 (2009), 197-215. https://doi.org/10.1080/13613320902995475 arXiv:https://doi.org/10.1080/13613320902995475 
[79] Nichole Pinkard, Sheena Erete, Caitlin K. Martin, and Maxine McKinney de Royston. 2017. Digital youth divas: Exploring narrative-driven curriculum to spark middle school girls' interest in computational activities. fournal of the Learning Sciences 26, 3 (2017), 477-516. https://doi.org/10.1080/10508406.2017.1307199

[80] Yolanda Rankin, Maedeh Agharazidermani, and Jakita Thomas. 2020. The role of familial influences in African American women's persistence in computing. In 2020 Research on Equity and Sustained Participation in Engineering, Computing, and Technology (RESPECT'20). 1-8.

[81] Yolanda A. Rankin and Jakita O. Thomas. 2019. Straighten up and fly right: Rethinking intersectionality in HCI research. Interactions 26, 6 (Oct. 2019), 64-68. https://doi.org/10.1145/3363033

[82] Yolanda A. Rankin and Jakita O. Thomas. 2020. The intersectional experiences of Black women in computing. In Proceedings of the 51st ACM Technical Symposium on Computer Science Education (SIGCSE'20). Association for Computing Machinery, New York, NY, 199-205. https://doi.org/10.1145/3328778.3366873

[83] Yolanda A. Rankin, Jakita O. Thomas, and Sheena Erete. 2021. Real talk: Saturated sites of violence in CS education. In Proceedings of the 52nd ACM Technical Symposium on Computer Science Education (SIGCSE'21). Association for Computing Machinery, New York, NY, 802-808. https://doi.org/10.1145/3408877.3432432

[84] Yolanda A. Rankin, Jakita O. Thomas, and India Irish. 2019. Food for thought: Supporting African American women's computational algorithmic thinking in an intro CS course. In Proceedings of the 50th ACM Technical Symposium on Computer Science Education (SIGCSE'19). Association for Computing Machinery, New York, NY, 641-646. https: //doi.org/10.1145/3287324.3287484

[85] Yolanda A. Rankin, Jakita O. Thomas, and Nicole M. Joseph. 2020. Intersectionality in HCI: Lost in translation. Interactions 27, 5 (Sept. 2020), 68-71. https://doi.org/10.1145/3416498

[86] Sanjay Reddy. 2020. On Performative Academic Anti-Racism. https://reddytoread.com/2020/06/02/on-performativeacademic-anti-racism/.

[87] A. Roberson, C. K. Martin, N. Pinkard, and Sheena L. Erete. 2015. Flip the switch: Generating girls' interest in STEM through E-fashion. International Society for Technology in Education (2015).

[88] Eric S. Roberts, Marina Kassianidou, and Lilly Irani. 2002. Encouraging women in computer science. SIGCSE Bulletin 34, 2 (June 2002), 84-88. https://doi.org/10.1145/543812.543837

[89] Monique Ross, Zahra Hazari, Gerhard Sonnert, and Philip Sadler. 2020. The intersection of being Black and being a woman: Examining the effect of social computing relationships on computer science career choice. ACM Transactions on Computing Education 20, 2 (Feb. 2020), Article 9, 15 pages. https://doi.org/10.1145/3377426

[90] Jean J. Ryoo. 2019. Pedagogy that supports computer science for all. ACM Transactions on Computing Education 19, 4 (July 2019), Article 36, 23 pages. https://doi.org/10.1145/3322210

[91] G. Michael Schneider and Judith L. Gersting. 2018. Invitation to Computer Science. Course Technology.

[92] Kimberly A. Scott and Steve Elliott. 2020. STEM diversity and inclusion efforts for women of color: A critique of the new labor system. International fournal of Gender, Science, and Technology 11, 3 (2020), 375-382.

[93] Jay Shambaugh, Ryan Nunn, and Stacey A. Anderson. 2019. How Racial and Regional Inequality Affect Economic Opportunity. https:/www.brookings.edu/blog/up-front/2019/02/15/how-racial-and-regional-inequalityaffect-economic-opportunity/.

[94] Kimberly M. Sheridan, Kevin Clark, and Asia Williams. 2013. Designing games, designing roles: A study of youth agency in an urban informal education program. Urban Education (2013), 1-27. https://doi.org/10.1177/ 0042085913491220

[95] A. Solomon, D. Moon, A. L. Roberts, and J. E. Gilbert. 2018. Not just Black and not just a woman: Black women belonging in computing. In 2018 Research on Equity and Sustained Participation in Engineering, Computing, and Technology (RESPECT'18). 1-5.

[96] Daniel G. Solorzano and Tara J. Yosso. 2002. Critical race methodology: Counter-storytelling as an analytical framework for education research. Qualitative Inquiry 8, 23 (2002), 23-44. https://www.researchgate.net/publication/ 249735081_Critical_Race_Methodology_Counter-Storytelling_as_an_Analytical_Framework_for_Education Research.

[97] Shannon Sullivan. 2013. Inheriting racist disparities in health: Epigenetics and the transgenerational effects of white racism. Critical Philosophy of Race 1, 2 (2013), 190-218. http://www.jstor.org/stable/10.5325/critphilrace.1.2.0190.

[98] Elizabeth Sullivan-Hasson. 2021. TrustRadius 2021 Women in Tech Report. https://www.trustradius.com/buyer-blog/ women-in-tech-report.

[99] Valerie E. Taylor. 2002. Women of color in computing. SIGCSE Bulletin 34, 2 (June 2002), 22-23. https://doi.org/10. $1145 / 543812.543821$

[100] Joy Teague. 2002. Women in computing: What brings them to it, what keeps them in it? SIGCSE Bulletin 34, 2 (June 2002), 147-158. https://doi.org/10.1145/543812.543849

[101] Jakita O. Thomas. 2018. The computational algorithmic thinking (CAT) capability flow: An approach to articulating CAT capabilities over time in African-American middle-school girls. In Proceedings of the 49th ACM Technical 
Symposium on Computer Science Education (SIGCSE'18). Association for Computing Machinery, New York, NY, 149-154. https://doi.org/10.1145/3159450.3159473

[102] Jakita O. Thomas, Nicole Joseph, Arian Williams, Chanrtel Crum, and Jamika Burge. 2018. Speaking truth to power: Exploring the intersectional experiences of Black women in computing. In Proceedings of the 2018 Research on Equity and Sustained Participation in Engineering, Computing, and Technology (RESPECT'18). https://doi.org/10.1109/ RESPECT.2018.8491718

[103] Jakita O. Thomas, Yolanda Rankin, Rachelle Minor, and Li Sun. 2017. Exploring the difficulties African-American middle school girls face enacting computational algorithmic thinking over three years while designing games for social change. Computer Supported Cooperative Work: CSCW: An International fournal (2017). https://doi.org/10.1007/ s10606-017-9292-y

[104] A. Nicki Washington, Legand Burge, Marlon Mejias, Ketly Jean-Pierre, and Qi'Anne Knox. 2015. Improving undergraduate student performance in computer science at historically black colleges and universities (HBCUs) through industry partnerships. In Proceedings of the 46th ACM Technical Symposium on Computer Science Education (SIGCSE'15). Association for Computing Machinery, New York, NY, 203-206. https://doi.org/10.1145/2676723.2677277

[105] G. J. Washington, M. Meijias, and L. Burge. 2020. Understanding how to engage black HS boys in computer science through tech innovation and entrepreneurship. Computing in Science Engineering 22, 5 (2020), 20-28.

[106] Tiffani Williams. 2020. "Underrepresented Minority" Considered Harmful, Racist Language. https://cacm.acm.org/ blogs/blog-cacm/245710-underrepresented-minority-considered-harmful-racist-language/fulltext\#comments.

[107] Ryoko Yamaguchi and Jamika D. Burge. 2019. Intersectionality in the narratives of Black women in computing through the education and workforce pipeline. fournal for Multicultural Education (2019).

[108] Stuart Zweben and Betsy Bizot. 2014. 2013 CRA Taulbee survey. Computing Research Newsletter (CRN) 26, 5 (2014), $10-55$.

[109] Stuart Zweben and Betsy Bizot. 2015. 2014 CRA Taulbee survey. Computing Research Newsletter (CRN) 27, 5 (2015), $2-51$.

[110] Stuart Zweben and Betsy Bizot. 2018. 2017 CRA Taulbee survey. Computing Research Newsletter (CRN) 30, 5 (2018), $2-48$.

[111] Stuart Zweben and Betsy Bizot. 2019. 2018 CRA Taulbee survey. Computing Research Newsletter (CRN) 31, 5 (2019), $3-74$.

[112] Stuart Zweben and Betsy Bizot. 2020. 2019 CRA Taulbee survey. Computing Research Newsletter (CRN) 32, 5 (2020), $3-74$.

Received June 2020; revised April 2021; accepted June 2021 